Supporting Information for:

\title{
Boosting Oxygen Reduction of Single Iron Active Sites via Geometric and Electronic Engineering: Nitrogen and Phosphorus Dual Coordination
}

Kai Yuan, ${ }^{*,+\ddagger}$ Dirk Lützenkirchen-Hecht, ${ }^{\S}$ Longbin Li, ${ }^{\dagger}$ Ling Shuai, ${ }^{\|}$Yizhe Li, ${ }^{\dagger}$ Rui Cao, ${ }^{\perp}$ Ming Qiu, ${ }^{*, l}$ Xiaodong Zhuang, ${ }^{*, *}$ Michael K. H. Leung, ${ }^{\nabla}$ Yiwang Chen, ${ }^{*, \dagger}$ and Ullrich Scherf ${ }^{\ddagger}$

${ }^{\dagger}$ College of Chemistry/Institute of Polymers and Energy Chemistry, Nanchang University, 999 Xuefu Avenue, Nanchang 330031, China

${ }^{\ddagger}$ Macromolecular Chemistry Group (buwmakro) and Institute for Polymer Technology, Bergische Universität Wuppertal, Gauss-Str. 20, D-42119 Wuppertal, Germany

${ }^{\S}$ Faculty of Mathematics and Natural Sciences-Physics Department and Institute for Polymer Technology, Bergische Universität Wuppertal, Gauss-Str. 20, D-42119 Wuppertal, Germany

"Institute of Nanoscience and Nanotechnology, College of Physical Science and Technology, Central China Normal University, 430079 Wuhan, China

${ }^{\perp}$ Stanford Synchrotron Radiation Lightsource (SSRL), SLAC National Accelerator Laboratory, Menlo Park, California 94025, United States

"The Soft2D Lab, Shanghai Key Laboratory of Electrical Insulation and Thermal Ageing, State Key Laboratory of Metal Matrix Composites, School of Chemistry and Chemical Engineering, Shanghai Jiao Tong University, Dongchuan Road 800, 200240 Shanghai, China

${ }^{\nabla}$ Institution Ability R\&D Energy Research Centre, School of Energy and Environment, City University of Hong Kong, Hong Kong, China 


\section{Material Synthesis and Characterizations}

Materials. All reagents, unless otherwise stated, were obtained from commercial sources (Sigma Aldrich, Alfa Aesar and Acros) and were used without further purification.

Synthesis of polypyrrole (PPy) hydrogel. In a typical synthesis, $400 \mu \mathrm{L}$ (6 mmol) pyrrole monomer and $0.921 \mathrm{~mL}$ (1 mmol) phytic acid (50\%, wt/wt in water, Aldrich) were mixed with $2 \mathrm{~mL}$ of ethanol/water (v/v=1:1) mixture. $2.24 \mathrm{~g}(13.8 \mathrm{mmol})$ of $\mathrm{FeCl}_{3}$ was dissolved into another $2 \mathrm{~mL}$ of ethanol/water $(\mathrm{v} / \mathrm{v}=1: 1)$ mixture. After cooling down to about $4{ }^{\circ} \mathrm{C}$, both solutions were mixed together quickly, then aged for $24 \mathrm{~h}$. To remove excess acid and by-products from polymerization, the resultant polypyrrole (PPy) hydrogel was purified by immersing in deionized (DI) water for $24 \mathrm{~h}$. Finally, the PPy hydrogel was dried at room temperature under vacuum.

Preparation of Fe-N/P-C catalysts. To obtain the Fe-N/P-C catalysts, the dry PPy hydrogel was pyrolyzed in an argon atmosphere for $2 \mathrm{~h}$ at a heating rate of $5{ }^{\circ} \mathrm{C} \mathrm{min}{ }^{-1}$. To determine the optimum conditions for the formation of Fe-N/P-C catalysts, different pyrolysis temperatures $\left(600,700,800,900\right.$, and $1000{ }^{\circ} \mathrm{C}$ ) were examined. The pyrolyzed products were leached in $1 \mathrm{M} \mathrm{H}_{2} \mathrm{SO}_{4}$ solution for $8 \mathrm{~h}$ at $80{ }^{\circ} \mathrm{C}$, filtered and washed with plenty of de-ionized (DI) water, and then dried under vacuum. The obtained samples were denoted as Fe-N/P-C-600, Fe-N/P-C-700, Fe-N/P-C-800, FeN/P-C-900, and Fe-N/P-C-1000, respectively.

Preparation of N,P co-doped porous carbons (N/P-C). Similar to the synthesis of FeN/P-C, $400 \mu \mathrm{L}$ (6 mmol) pyrrole monomer and $0.921 \mathrm{~mL}$ (1 mmol) phytic acid (50\%, wt/wt in water, Aldrich) were mixed with $2 \mathrm{~mL}$ of ethanol/water (v/v=1:1) mixture. 684 mg (3 mmol) of ammonium persulphate was dissolved into another $2 \mathrm{~mL}$ of ethanol/water $(\mathrm{v} / \mathrm{v}=1: 1)$ mixture. After cooling down to about $4{ }^{\circ} \mathrm{C}$, both solutions were 
mixed together, then aged for $24 \mathrm{~h}$. To remove by-products from polymerization, the resultant PPy hydrogel was purified with DI water and freeze-dried, and then pyrolyzed at $700{ }^{\circ} \mathrm{C}$ for $2 \mathrm{~h}$ in an argon atmosphere at a heating rate of $5{ }^{\circ} \mathrm{C} \mathrm{min}^{-1}$. The obtained sample was named N/P-C-700.

Preparation of $\mathbf{N}$-doped porous carbons (N-C). Nitrogen doped porous carbons (NC) was also prepared by the same procedure of N/P-C except adding phytic acid. The obtained sample was named N-C-700.

Preparation of Fe-N-C-700 catalyst. For the synthesis of Fe-N-C-700 catalyst, iron phenanthroline solution (10 mg of $\mathrm{FeCl}_{2} 6 \mathrm{H}_{2} \mathrm{O}$ and $30 \mathrm{mg}$ of 1,10-phenanthroline in 2 $\mathrm{mL}$ of ethanol) was dropped to $100 \mathrm{mg}$ of $\mathrm{N}-\mathrm{C}-700$, and the mixture was well ground until solution evaporation. Then, the powder was dried at $80{ }^{\circ} \mathrm{C}$. After ball-milled, the powder was carbonized at $700{ }^{\circ} \mathrm{C}$ for $2 \mathrm{~h}$ in an argon atmosphere at a heating rate of 5 ${ }^{\circ} \mathrm{C} \mathrm{min}^{-1}$. The final product was etched by1 $\mathrm{M} \mathrm{H}_{2} \mathrm{SO}_{4}$ at $80{ }^{\circ} \mathrm{C}$ to produce Fe-N-C-700.

Preparation of Fe-N $\mathbf{N}_{4} @ N / P-C-700$ catalyst. The preparation process of Fe-N 4 @N/PC-700 catalyst was the same as that of the Fe-N-C-700 catalyst except that N/P-C-700 was used as the carbon source.

Characterizations. Scanning electron microscopy (SEM) measurements were performed on a Quanta 200F environmental scanning electron microscope (FEI, The Netherlands). Transmission electron microscopy (TEM) images, high resolution TEM (HRTEM) images, selected area electron diffraction (SAED) patterns, energy dispersive X-ray spectroscopy (EDS) elemental mapping and high angle annular darkfield scanning TEM (HAADF-STEM) were performed by a JEM-2100F (field emission) scanning transmission electron microscope (JEOL, JEM-2100F) with an acceleration voltage of $200 \mathrm{kV}$. Raman spectra were recorded on a LabRAM HR Raman Microscope with an excitation wavelength of $633 \mathrm{~nm}$. X-ray powder diffraction (XRD) patterns were recorded on a Rigaku SmartLab Intelligent X-ray diffraction system with filtered 
$\mathrm{Cu} \mathrm{K} \alpha$ radiation ( $\lambda=1.5406 \AA$, operating at $45 \mathrm{kV}$ and $200 \mathrm{~mA}$ ) and a PANalytical Empyrean diffractometer with $\mathrm{Cu} \mathrm{K} \alpha$ radiation $(\lambda=1.5406 \AA$, operating at $40 \mathrm{kV}$ and $40 \mathrm{~mA}$ ). The nitrogen adsorption-desorption measurements were performed on a BELSORB Max (BEL Japan Inc.). The surface areas were calculated using the Brunauer-Emmett-Teller (BET) model in the pressure range $p / p_{0}$ from $0.05-0.3$. The total pore volume was determined at a relative pressure of 0.99 . The pore size distribution was analyzed from the nitrogen adsorption data using a non-linear density functional theory (NL-DFT) method with a slit pore model. X-ray photoelectron spectroscopy (XPS) was carried out on a Kratos AXIS Ultra, performing at $15 \mathrm{kV}$ and $15 \mathrm{~mA}$ with a monochromatic $\mathrm{Al} \mathrm{K \alpha}$ source $(\mathrm{h} v=1486.71 \mathrm{eV})$. XPS data analysis comprised a Shirley background subtraction and a least-square fitting procedure of the spectra using XPSPEAK software.

General information about EXAFS measurement, data reduction and fitting. The ex-situ EXAFS measurements at the Fe K-edge (7112 eV) were conducted at beamline BL10 at the DELTA storage ring (Dortmund, Germany) operating with 100-130 mA of stored 1.5 GeV electrons and at the Stanford Synchrotron Radiation Lightsource (SSRL) under standard ring conditions of $3 \mathrm{GeV}$ and $500 \mathrm{~mA}$ on the unfocused 20-pole $2 \mathrm{~T}$ wiggler side station 7-3, equipped with a $\mathrm{Si}(220)$ double crystal monochromator for energy selection. For these experiments, the X-rays from the wiggler source were monochromatized by a Si (111) channel-cut monochromator, and $\mathrm{N}_{2}$-filled ionization chambers were employed as detectors for the incident and transmitted X-ray intensities. The fluorescence radiation from the sample was collected using a large-area photodiode, and a third, Ar-filled ionization chamber was used to monitor an iron metal reference sample simultaneously with the actual samples under investigation for a precise energy calibration. The EXAFS data analysis was performed using the Athena/Artemis software packages. Several Fe reference compounds (such as FePc (Fe-phthalocyanine $\mathrm{C}_{32} \mathrm{H}_{16} \mathrm{FeN}_{8}$ ), $\mathrm{Fe}_{2} \mathrm{P}, \mathrm{FeO}, \mathrm{Fe}_{2} \mathrm{O}_{3}, \mathrm{Fe}_{3} \mathrm{O}_{4}$ ) were measured for comparison.

For the fits of the Fe K-edge EXAFS data of Fe-N/P-C-700, the $k^{2}$-weighted $\chi(k)$ was 
Fourier-transformed into $R$-space in the $k$-range from $1.45 \AA^{-1}<k<10.64 \AA^{-1}$. The data belonging to the first coordination sphere around Fe in the radial distance from $1 \AA<$ $R<2.26$ Å were fitted using phases and amplitudes calculated by FEFF 8 (Phys. Rev. $B, 1998,58,7565-7576$.). Due to the similarity of the Fourier-transform of sample FeN/P-C-700 to that of FePc with 4 nitrogen atoms in about $1.97 \AA$ radial distance, it can be expected that $\mathrm{N}$-bonds also dominate the first shell for the sample under investigation. Thus, starting with a square planar arrangement of $\mathrm{N}_{1}$ neighbouring $\mathrm{N}$-atoms in a distance $\mathrm{R}_{1}$ and a mean-squared disorder $\sigma_{1}{ }^{2}$, a finite number of $\mathrm{N}_{2}$ neighbouring $\mathrm{P}$ atoms in a distance $\mathrm{R}_{2}$ was assumed in the fit. Due to the different atomic radii of $\mathrm{N}$ and $P, R_{2}$ is expected to be substantially larger than $R_{1}$. Furthermore, an identical disorder in both shells (i.e. $\sigma_{1}{ }^{2}=\sigma_{2}{ }^{2}$ ) and a global value for the inner potential shift ( $\Delta E_{0}$ ) was assumed, so that in total 6 independent fit parameters were used, so that, in relation to the number of independent data points $\mathrm{N}_{\mathrm{idp}} \approx 8$ resulting from the used ranges in $k$ - and $R$-space, the fits appear statistically meaningful. The fit residuals were minimized in a least-square fit using $k^{2}$-weighted data in both $R$ - and $k$-space, yielding an $R$-factor of 0.020 . A typical fit result is shown in Table S2. The optimization of the fit yields $\mathrm{N}_{1}=2.5 \pm 0.3, \mathrm{R}_{1}=2.00 \AA \pm 0.01 \AA, \mathrm{N}_{2}=0.7 \pm 0.1, \mathrm{R}_{2}=2.37 \AA \pm 0.02 \AA$, $\sigma_{1}^{2}=\sigma_{2}{ }^{2}=(2.49 \pm 0.18) * 10^{-3} \AA^{2}$ and $\Delta E_{0}=-2.0 \pm 1.1 \mathrm{eV}$. Since the fitted number of nearest neighbours is also substantially smaller for FePc, i.e. for this sample $\mathrm{N}_{1}$ was determined to $b e \approx 3.2$, we may scale all the determined nearest neighbour numbers by 4/3.2, this way, $\mathrm{N}_{1}$ results to ca. 3.1 , and $\mathrm{N}_{2} \approx 0.9$. Thus it can be concluded that approximated $3 \mathrm{~N}$ atoms in about $2 \AA$ and one P-atoms in about $2.35 \AA$ are coordinated around Fe.

As above, for the fits of the Fe K-edge EXAFS data of Fe-N/P-C-800, the $k^{2}$-weighted $\chi(\mathrm{k})$ was used. However, the k- and R-ranges for the fits were different, i.e. $2.20 \AA^{-1}<$ $k<10.67 \AA^{-1}$ and $1 \AA<\mathrm{R}<3.27 \AA$, respectively. In particular due to the larger range in $R$-space, the number of independent data points increases to $\mathrm{N}_{\text {idp }} \approx 12$ here. $\mathrm{A}$ modelling of the data with the same approach compared to sample Fe-N/P-C-700 did not lead to meaningful results, thus, in particular due to the results of the X-ray 
diffraction studies that suggest the presence of $\mathrm{Fe}_{2} \mathrm{P}$ nanoparticles, we have used a different structure as starting point for the fits. According to the literature (Acta Chem. Scand. 1959, 13, 425-432), $\mathrm{Fe}_{2} \mathrm{P}$ crystallizes in the hexagonal space group P-62m (no \#189), with $\mathrm{a}=\mathrm{b}=5.811 \AA, \mathrm{c}=3.431 \AA, \alpha=\beta=90^{\circ}$ and $\gamma=120^{\circ}$, in which iron occupies three symmetry equivalent tetrahedral and three symmetry equivalent square pyramidal sites, and three $\mathrm{P}$ atoms are distributed in the lattice. The crystal structure mainly results in two short Fe-P interactions with a single $\mathrm{P}$ in a distance $\mathrm{R}_{1}=2.37 \AA$ and a group of 4 phospors at $\mathrm{R}_{2}=2.46 \AA$, and two Fe-Fe coordinations with $\mathrm{N}=2$ and $\mathrm{N}=4$ at $\mathrm{R}_{3}=2.59 \AA$ and $\mathrm{R}_{4}=2.70 \AA$, respectively.

We have thus assumed individual fit parameters for the bond length and the disorder of the two Fe-P and Fe-Fe bonds in comparison to the bulk $\mathrm{Fe}_{2} \mathrm{P}$ structure, and related amplitude reduction factors. Furthermore, a global value for the inner potential shift $\left(\Delta E_{0}\right)$ was assumed, so that in total 7 independent fit parameters resulted here. As can be seen in Figure S23 and Figure S24, the experimental data are well-reproduced by the fit with an $R$-factor of 0.017 . However, we have determined slightly reduced Fe-P bond distances of $\mathrm{R}_{1}=2.19 \AA$ and $\mathrm{R}_{2}=2.28 \AA$, while the Fe-Fe bonds are almost identical to the bulk values with a decrease by $0.02 \AA$ only. The disorder $\sigma_{1}{ }^{2}=\sigma_{2}{ }^{2}=(8.71 \pm$ $0.45) * 10^{-3} \AA^{2}$ and $\sigma_{3}{ }^{2}=\sigma_{4}{ }^{2}=(2.22 \pm 0.30) * 10^{-3} \AA^{2}$ may reflect the increased disorder due to the small size of the particles.

Mössbauer measurements. The Mössbauer measurements were performed using a conventional spectrometer (Germany, Wissel MS-500) in transmission geometry with constant acceleration mode. $\mathrm{A}^{57} \mathrm{Co}(\mathrm{Pd})$ source with activity of $25 \mathrm{mCi}$ was used. The velocity calibration was done with a room temperature $\alpha$-Fe absorber. The spectra were fitted by the software Recoil using Lorentzian Site Analysis.

\section{Oxygen Reduction Reaction (ORR) Measurements}

Cyclic voltammetry (CV) and Rotating Disk Electrode (RDE) Measurements. First,

$10 \mathrm{mg}$ of the sample were blended with $500 \mu \mathrm{L}$ of a $1 \mathrm{wt} \%$ Nafion ethanol solution, 
and then sonicated until a homogeneous dispersion is formed. Next, a certain volume of the catalyst dispersion was pipetted onto a glassy carbon electrode with a diameter of $5 \mathrm{~mm}\left(0.6 \mathrm{mg} / \mathrm{cm}^{2}\right)$. For comparison, the Pt/C catalyst dispersion was prepared by dispersing $4 \mathrm{mg}$ of $\mathrm{Pt} / \mathrm{C}(20 \mathrm{wt} \% \mathrm{Pt})$ in $1 \mathrm{~mL}$ of ethanol with $35 \mu \mathrm{L}$ of $5 \mathrm{wt} \%$ Nafion solution (40 wt\% of Nafion to catalyst ratio). Next, $5 \mu \mathrm{L}$ of the Pt/C dispersion was loaded onto a glassy carbon electrode. The catalyst dispersion was dried slowly in air until a uniform catalyst distribution across the electrode surface was obtained.

Electrochemical measurements (cyclic voltammetry (CV), rotating disk electrode (RDE) and rotating ring-disk electrode (RRDE) measurements) were performed with a bipotentiostat (Pine Research Instrumentation, USA) in a three-electrode cell system. A rotating glassy carbon disk and platinum ring electrode (Pine Research Instrumentation, USA) after loading with the electrocatalyst were used as working electrode, an $\mathrm{Ag} / \mathrm{AgCl}(\mathrm{KCl}, 3 \mathrm{M})$ electrode as reference electrode, and a graphite rod as counter electrode. The electrochemical experiments were conducted in a $0.1 \mathrm{M} \mathrm{KOH}$ or $\odot .1 \mathrm{M} \mathrm{HClO}_{4}$ aqueous electrolyte saturated with oxygen by bubbling purified $\mathrm{O}_{2}$ gas for the oxygen reduction reaction. The potential range was cycled between -0.95 and $0.05 \mathrm{~V}$ at a scan rate of $20 \mathrm{mV} / \mathrm{s}$ at room temperature after purging $\mathrm{O}_{2}$ gas for 30 min through the cell. The flow of $\mathrm{O}_{2}$ was maintained through the electrolyte during recording of CVs. In control experiments, $\mathrm{CV}$ measurements were performed in a $\mathrm{N}_{2}$ saturated electrolyte. RDE measurements were scanned cathodically at a rate of $5 \mathrm{mV}$ $\mathrm{s}^{-1}$ for different rotating speeds from 225 to $1600 \mathrm{rpm}$. Linear sweep voltammetry (LSV) curves for the oxygen evolution reaction (OER) were recorded in $0.1 \mathrm{M} \mathrm{KOH}$ solution by RDE at $1600 \mathrm{rpm}$ at $5 \mathrm{mV} \mathrm{s}^{-1}$. All the ORR and OER currents presented in the figures are Faradaic currents, i.e., after correction for the capacitive current. All the curves were iR corrected and each catalyst was repeated at least 3 times for the above measurements to exclude possible incidental errors. The applied potential vs. $\mathrm{Ag} / \mathrm{AgCl}(3 \mathrm{M} \mathrm{KCl})$ is converted to reversible hydrogen electrode (RHE) potential using the following equation:

$$
\mathrm{ERHE}_{\mathrm{RH}}=\mathrm{EAg} / \mathrm{AgCl}+0.059 \mathrm{pH}+\mathrm{E}^{\circ} \mathrm{Ag} / \mathrm{AgCl}
$$


where $\mathrm{EAg} / \mathrm{AgCl}$ was the experimentally measured potential using $\mathrm{Ag} / \mathrm{AgCl}$ as the reference electrode and $\mathrm{E}^{\circ} \mathrm{Ag} / \mathrm{AgCl}$ was $0.210 \mathrm{~V}$

The Koutecky-Levich $(K-L)$ plots $\left(J^{-1}\right.$ vs $\left.\omega^{-1 / 2}\right)$ were analyzed at various electrode potentials. The slopes of the linear lines were used to calculate the number of electrons transferred ( $n$ ) per oxygen molecule in the ORR process at the electrodes according to the $K-L$ equation, and $J_{K}$ can be calculated from the inverse of intercept.

$\frac{1}{J}=\frac{1}{J_{L}}+\frac{1}{J_{K}}=\frac{1}{B \omega^{1 / 2}}+\frac{1}{J_{K}}$

$B=0.62 n F C_{0}\left(D_{0}\right)^{2 / 3} v^{-1 / 6}$

$J_{K}=n F k C_{0}$

where $J$ is the measured current density, $J_{K}$ and $J_{L}$ are the kinetic- and diffusion limiting current densities, $\omega$ is the angular velocity of the rotating electrode $(\omega=2 \pi \mathrm{N}, \mathrm{N}$ is the linear rotation speed), $F$ is the Faraday constant $\left(F=96485 \mathrm{C} \mathrm{mol}^{-1}\right), C_{0}$ is the concentration of $\mathrm{O}_{2}$ in $0.1 \mathrm{M} \mathrm{KOH}\left(1.2 \times 10^{-3} \mathrm{M}\right), \mathrm{D}_{0}$ is the diffusion coefficient of $\mathrm{O}_{2}$ in $0.1 \mathrm{M} \mathrm{KOH}\left(1.9 \times 10^{-5} \mathrm{~cm}^{2} \mathrm{~s}^{-1}\right), v$ is the kinematic viscosity of the electrolyte $\left(0.01 \mathrm{~cm}^{2}\right.$ $\mathrm{s}^{-1}$ ), and $k$ is the electron transfer rate constant.

Rotating Ring-Disk Electrode (RRDE) Measurement. Catalyst inks and electrodes were prepared by the same method as above. The disk electrode was scanned cathodically at a rate of $5 \mathrm{mV} \mathrm{s}^{-1}$, and the ring potential was constant at $0.5 \mathrm{~V} v \mathrm{~s}$. $\mathrm{Ag} / \mathrm{AgCl}$. Based on the RRDE results, the $\mathrm{HO}_{2}{ }^{-}(\%)$ and the electron transfer number ( $n$ ) were determined by the following equations:

$$
\begin{aligned}
& n=\frac{4 I_{\text {Disk }}}{I_{\text {Disk }}+\frac{I_{\text {Ring }}}{N}} \\
& \%\left(\mathrm{HO}_{2}^{-}\right)=\frac{200 \times \frac{I_{\text {Ring }}}{N}}{I_{\text {Disk }}+\frac{I_{\text {Ring }}}{N}}
\end{aligned}
$$

where Idisk is disk current, Iring is ring current, and $N$ is current collection efficiency of the Pt ring, which was provided as 0.37 by the manufacturer. 
The chronoamperometric measurements was used to evaluate the durability for ORR. The addition of $3 \mathrm{~mL}$ methanol into electrolyte was used to examine the methanol tolerance of catalysts.

Zn-air batteries tests. Single-cell testing of the catalyst was performed using a multichannel potentiostat and a laboratory-constructed Zn-air battery. A polished Zn plate and a catalyst-coated gas diffusion layer (Hesen Electric Inc. (Shanghai), carbon paper HCP-120 with an area of $3.14 \mathrm{~cm}^{2}$ ) were used as the anode and cathode, respectively. In the Zn-air battery, a microporous membrane (25 $\mu \mathrm{m}$ polypropylene membrane, Celgard 5550) was used as the separator, stainless steel mesh was used as the current collector, and $6 \mathrm{M}$ aqueous $\mathrm{KOH}$ solution was used as electrolyte. Based on the battery design, the area of the gas diffusion layer exposed to the electrolyte was 3.14 $\mathrm{cm}^{2}$. All the catalysts studied in this work were coated onto the gas diffusion layer using an airbrush to achieve a loading of $\sim 3 \mathrm{mg} \mathrm{cm}^{-2}$. Briefly, $10 \mathrm{mg}$ of the catalyst material was dispersed in $0.9 \mathrm{~mL}$ of isopropanol and sonicated for $30 \mathrm{~min}$. Following this, 100 $\mu \mathrm{L}$ of $5 \mathrm{wt} \%$ Nafion solution was added, and the mixture sonicated for $30 \mathrm{~min}$ to form the catalyst ink. The catalyst ink was sprayed onto the gas diffusion layer with a conventional airbrush system. After spraying, the gas diffusion electrode was dried at $80^{\circ} \mathrm{C}$ for $1 \mathrm{~h}$. The catalyst loading was determined by the difference in the weight of the gas diffusion layer before and after spraying. Additionally, rechargeable Zn-air battery was fabricated using zinc plate as anode, catalyst sprayed on the gas diffusion layer as air-cathode, and $6 \mathrm{M} \mathrm{KOH}$ solution with $0.2 \mathrm{M}$ zinc acetate as electrolyte. The galvanostatic charge/discharge test was performed using a Land 2001A battery test system at room temperature.

First-principles calculations. All first-principles-based calculations were conducted by applying the Cambridge Serial Total Energy Package (CASTEP) in Material Studio which performs the density functional theory (DFT) plane-wave pseudopotential method to carry out first principles quantum mechanics calculations. In the calculation, 
the generalized gradient approximation (GGA) within Perdew-Burke-Ernzerhof (PBE) form was used as the exchange-correlation function. The convergence tests of the total energy with respect to the k-points sampling and the energy-cutoff were carefully examined, using $3 \times 3 \times 1$ Monkhorst-Pack k-points grid and a $900 \mathrm{eV}$ energy-cutoff for plane-wave expansion. Valence states used were Fe-3s $3 \mathrm{p}^{6} 3 \mathrm{~d}^{6} 4 \mathrm{~s}^{2}, \mathrm{P}-3 \mathrm{~s}^{2} 3 \mathrm{p}^{3}$, N$2 \mathrm{~s}^{2} 2 \mathrm{p}^{3}, \mathrm{O}-2 \mathrm{~s}^{2} 2 \mathrm{p}^{4}, \mathrm{C}-2 \mathrm{~s}^{2} 2 \mathrm{p}^{2}$ and $\mathrm{H}-1 \mathrm{~s}^{1}$. In the super-cell configuration, a sufficiently large vacuum slab (about $20 \AA$ ) was maintained. The SCF tolerance was setup to 1e $6 \mathrm{eV} \cdot$ atom $^{-1}$ for the geometrical optimization and phonon calculations. 


\section{Supporting Figures and Tables}

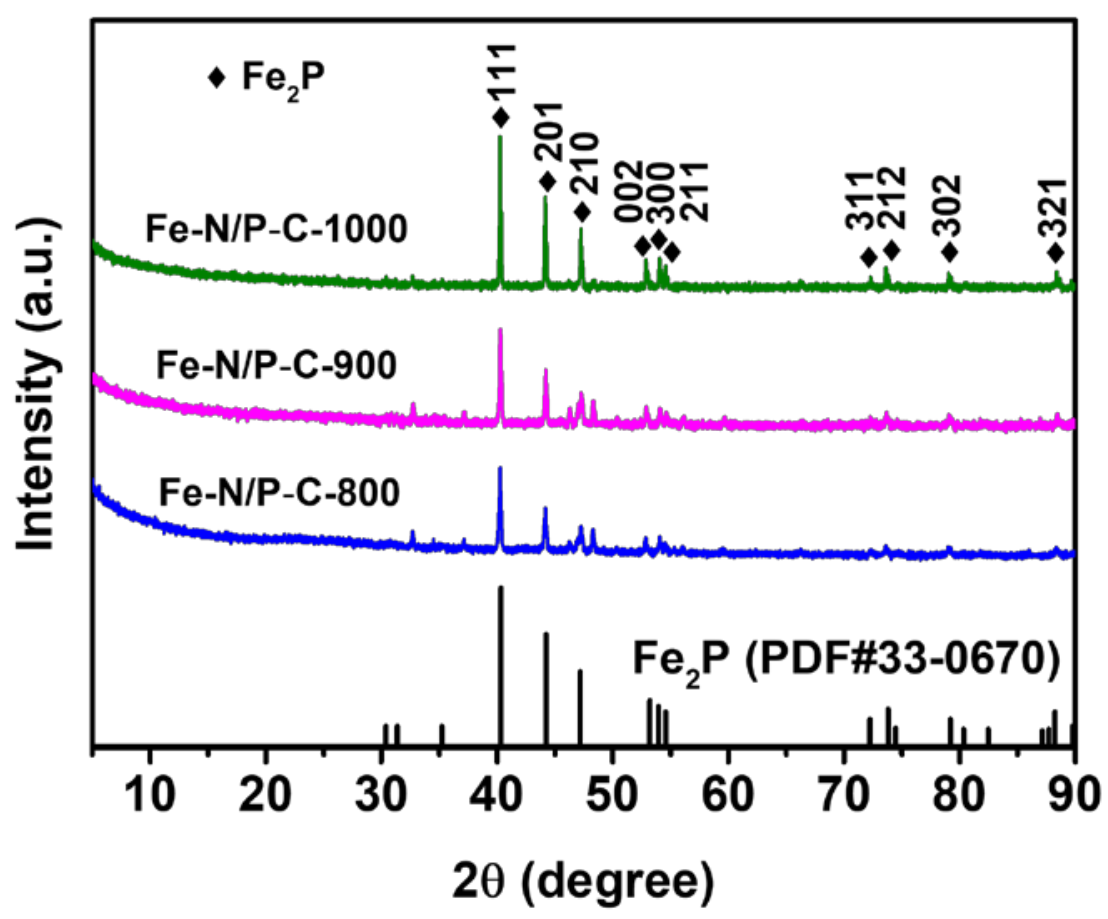

Figure S1. XRD patterns for the Fe-N/P-C samples prepared at different temperatures. We prepared Fe-N/P-C samples using identical fabrication methods except the calcination temperature. An amorphous structure in the XRD pattern was observed when the calcination temperature was set at $600{ }^{\circ} \mathrm{C}$ and $700{ }^{\circ} \mathrm{C}$. The structures belonging to $\mathrm{Fe}_{2} \mathrm{P}$ can be obtained after rising the calcination temperature up to $800{ }^{\circ} \mathrm{C}$. Intense Bragg peaks located at 40.3, 44.2, 47.2, 52.8, 54.1, 54.6, 72.3, 73.7, 79.1, and 88. $3^{\circ}$ can be assigned to the (111), (201), (210), (002), (300), (211), (311), (212), (302), and (321) crystal planes from the $\mathrm{Fe}_{2} \mathrm{P}$ phase (PDF\# 33-0670). 


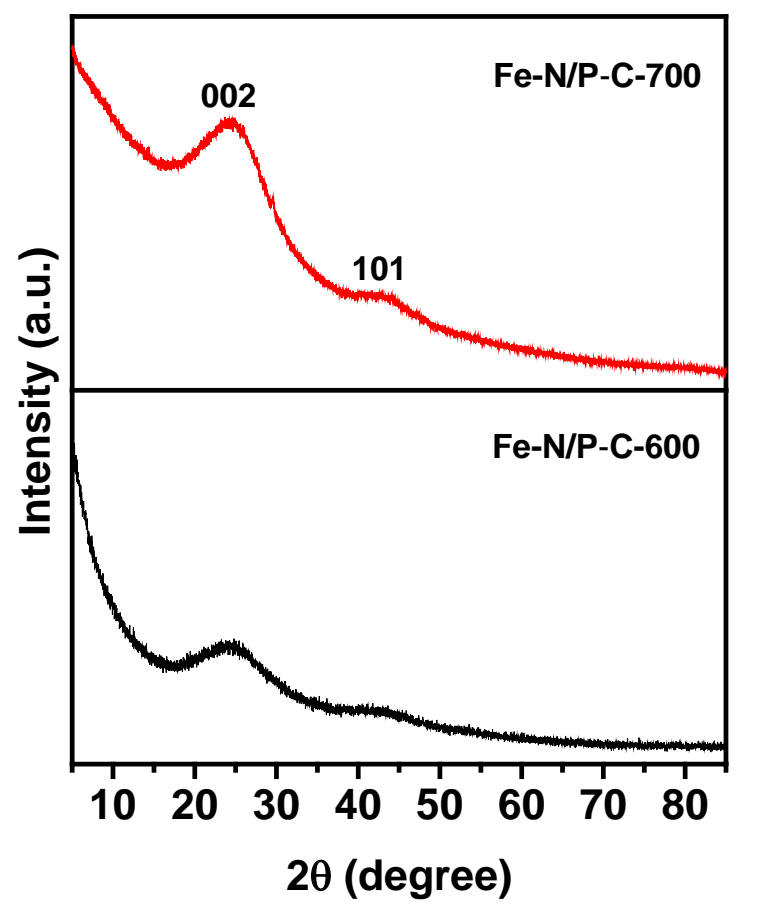

Figure S2. XRD patterns for the Fe-N/P-C-600 and Fe-N/P-C-700. Two broad peaks located at around $24.3^{\circ}$ and $42.6^{\circ}$ can be indexed to the (002) and (101) diffraction peaks of carbon, respectively. 


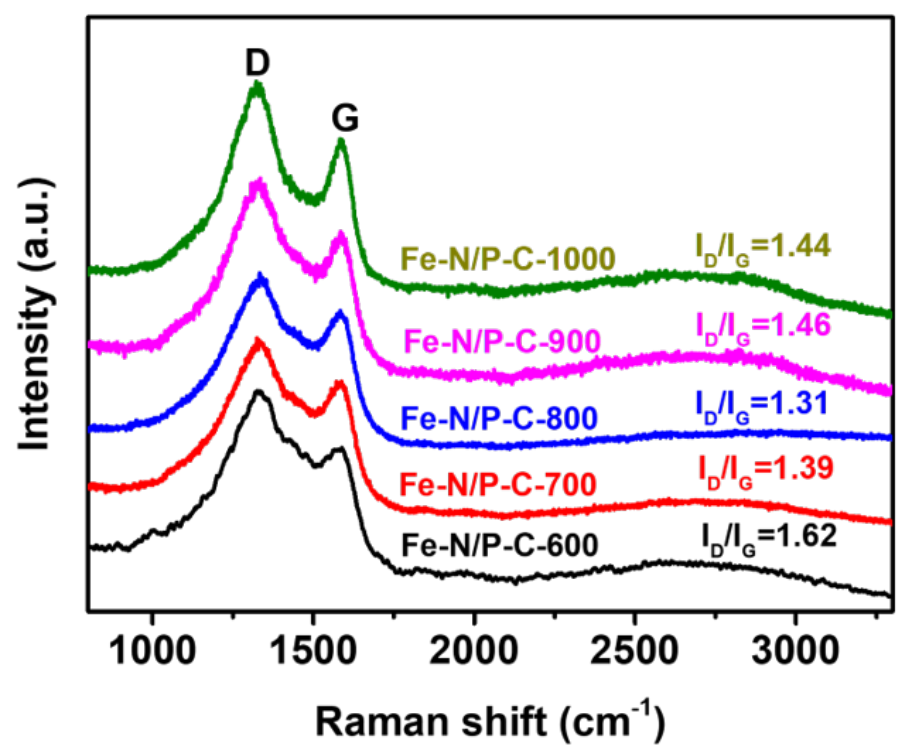

Figure S3. Raman spectra for the Fe-N/P-C- $X$ samples prepared at different temperatures.



Figure S4. SEM image of Fe-N/P-C-700. 

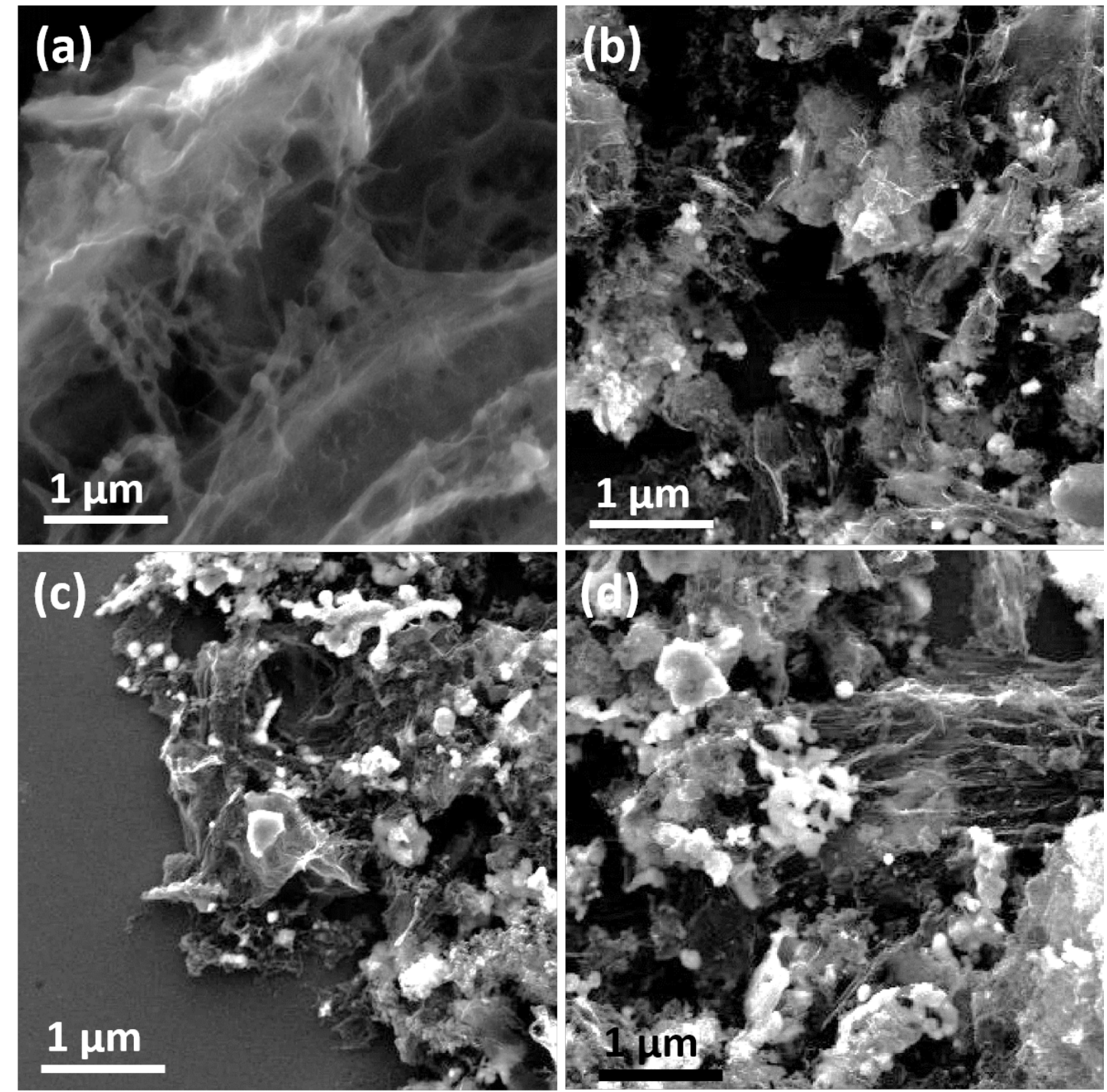

Figure S5. SEM images of (a) Fe-N/P-C-600, (b) Fe-N/P-C-800, (c) Fe-N/P-C-900 and (d) Fe-N/P-C-1000. 

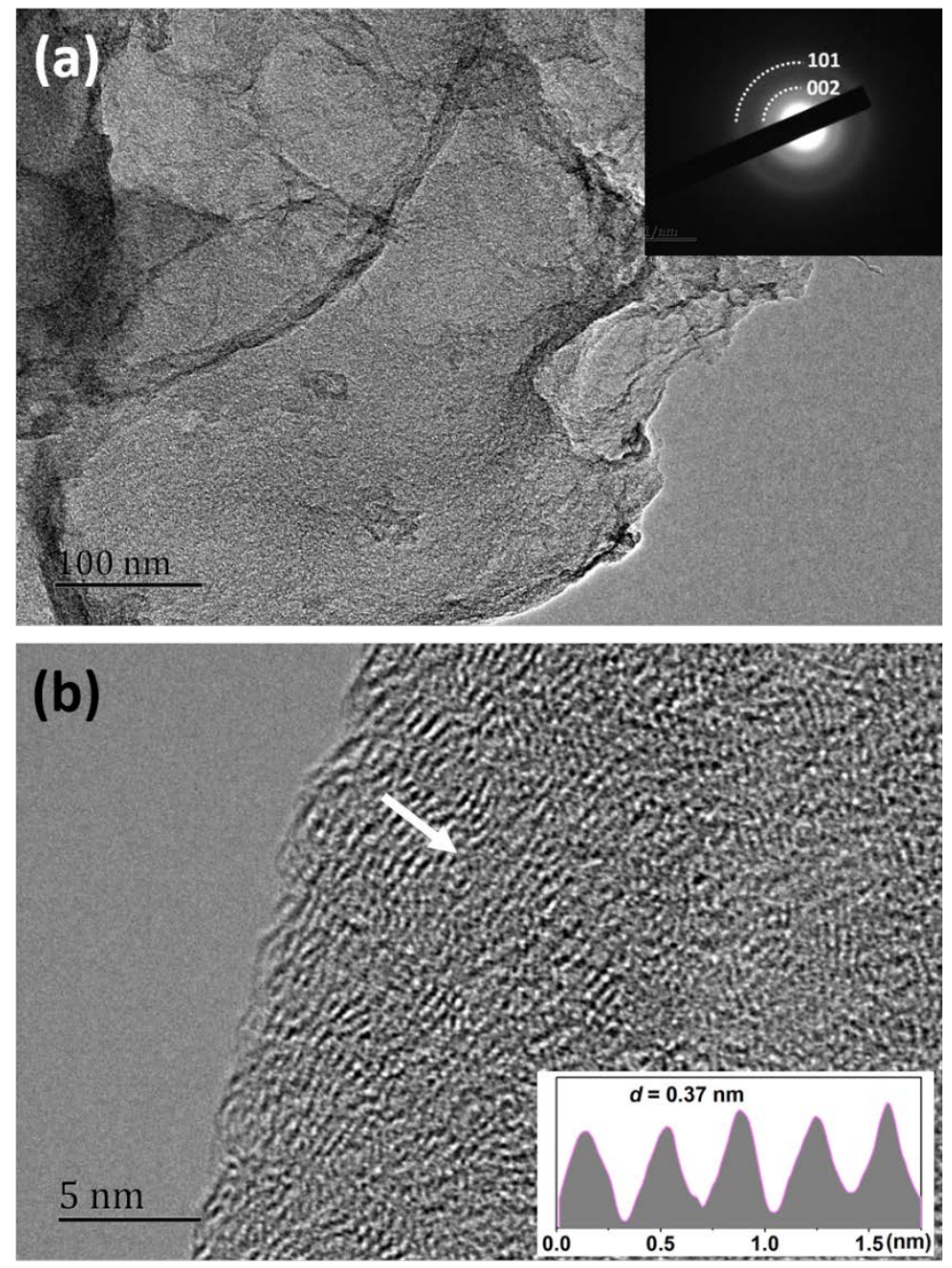

Figure S6. (a) TEM image and SAED pattern, (b) HRTEM image, and corresponding contrast profile along the arrow indicate interlayer spacing in the inset. 



Figure S7. TEM images, HRTEM images and selected-area electron diffraction (SAED) patterns of (a-c) Fe-N/P-C-600, (d-f) Fe-N/P-C-800, (g-i) Fe-N/P-C-900 and (j-l) FeN/P-C-1000. Well-resolved lattice fringe corresponding to $\mathrm{Fe}_{2} \mathrm{P}$ were observed when the pyrolysis temperature is increased to $800{ }^{\circ} \mathrm{C}$ or higher. 

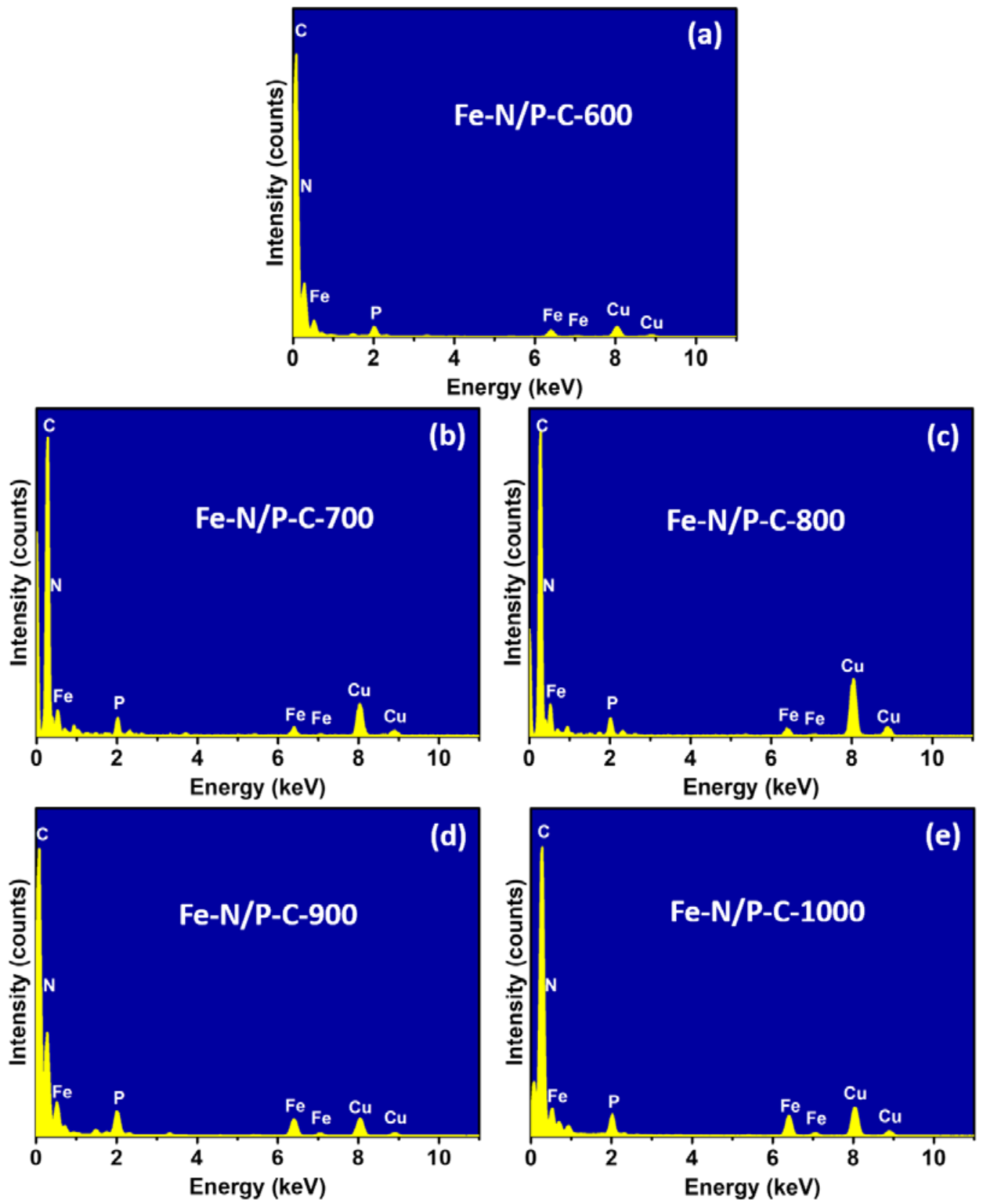

Figure S8. EDS spectra of Fe-N/P-C samples prepared at different temperatures. 


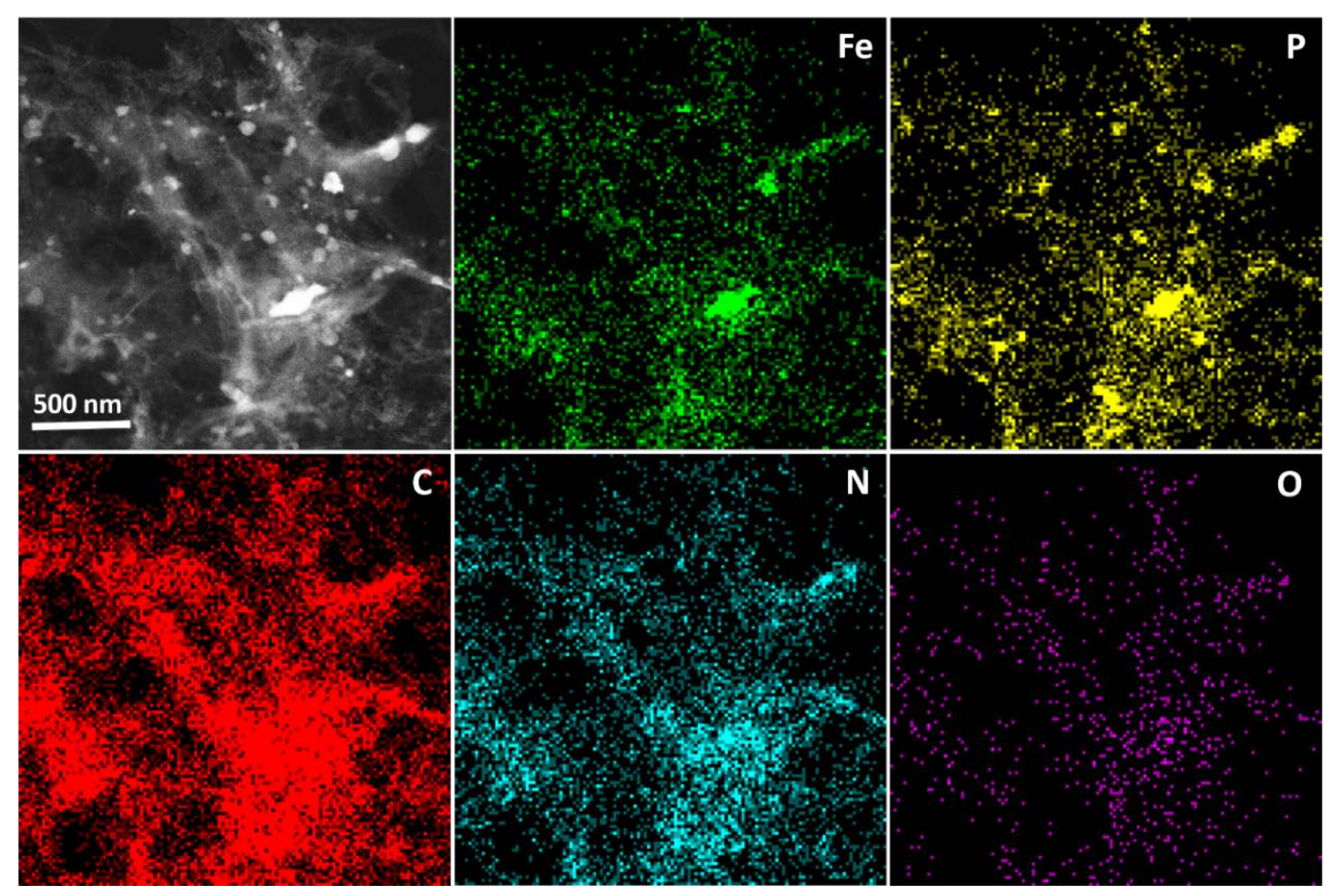

Figure S9. HAADF-STEM image with corresponding EDX mapping images of FeN/P-C-800. 


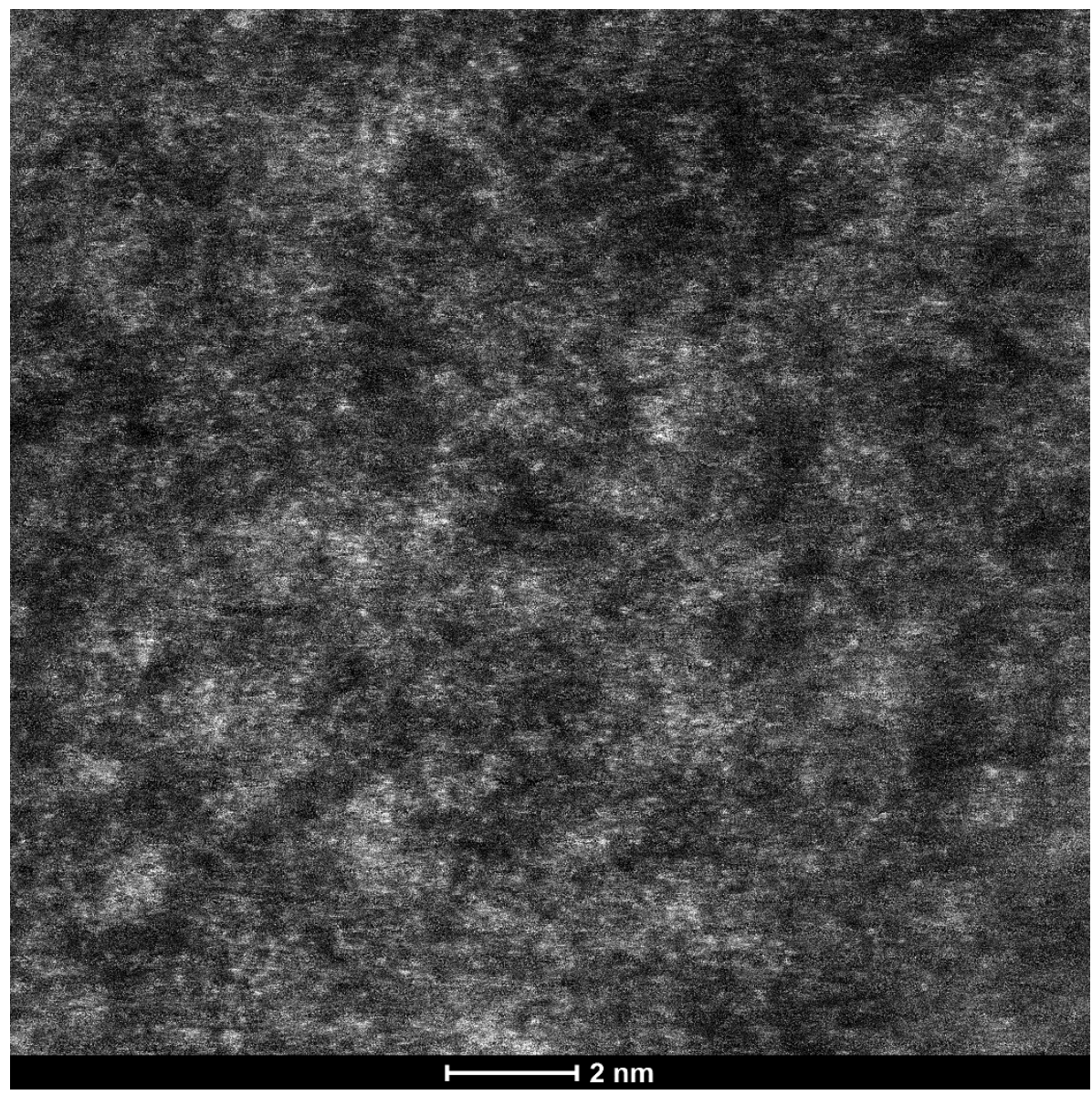

Figure S10. Aberration-corrected atomic-resolution HAADF-STEM image of Fe-N/PC-700. 


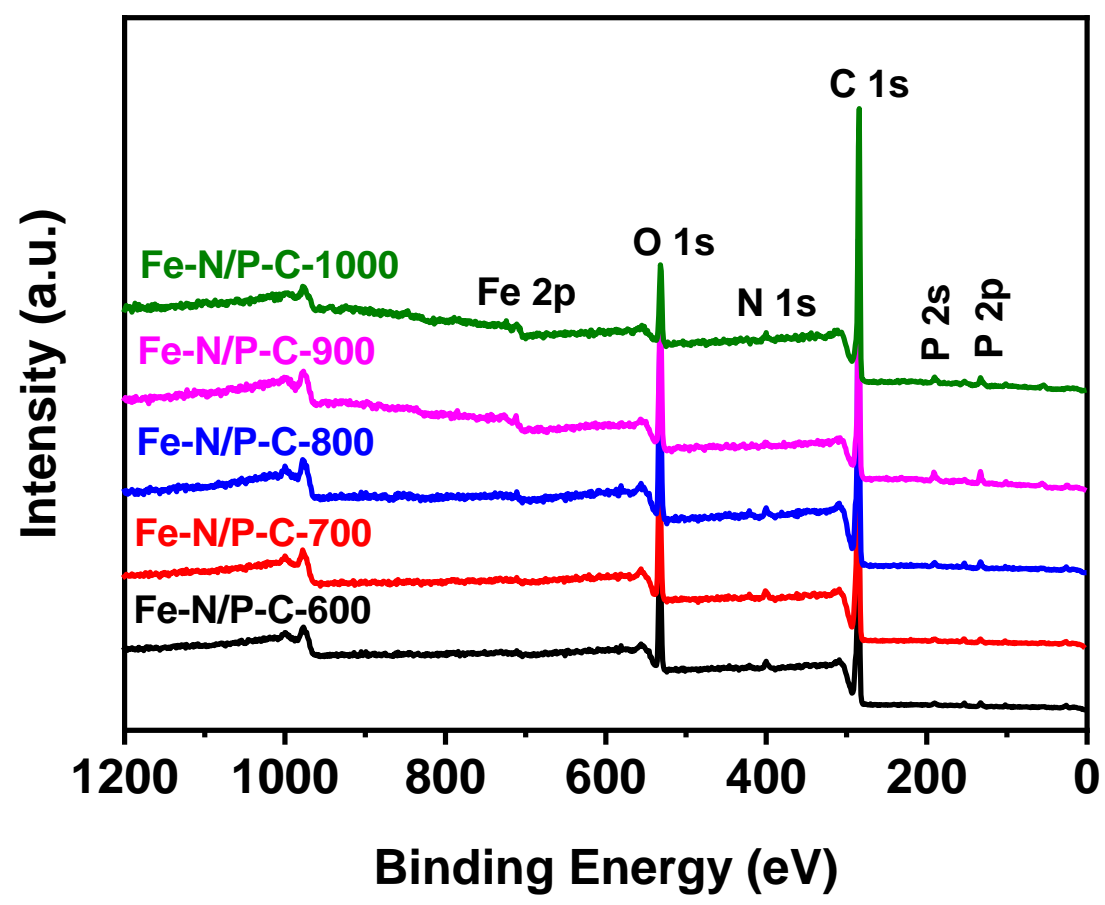

Figure S11. The survey XPS spectra of Fe-N/P-C samples prepared at different temperatures. The main elemental contributions are indicated. 


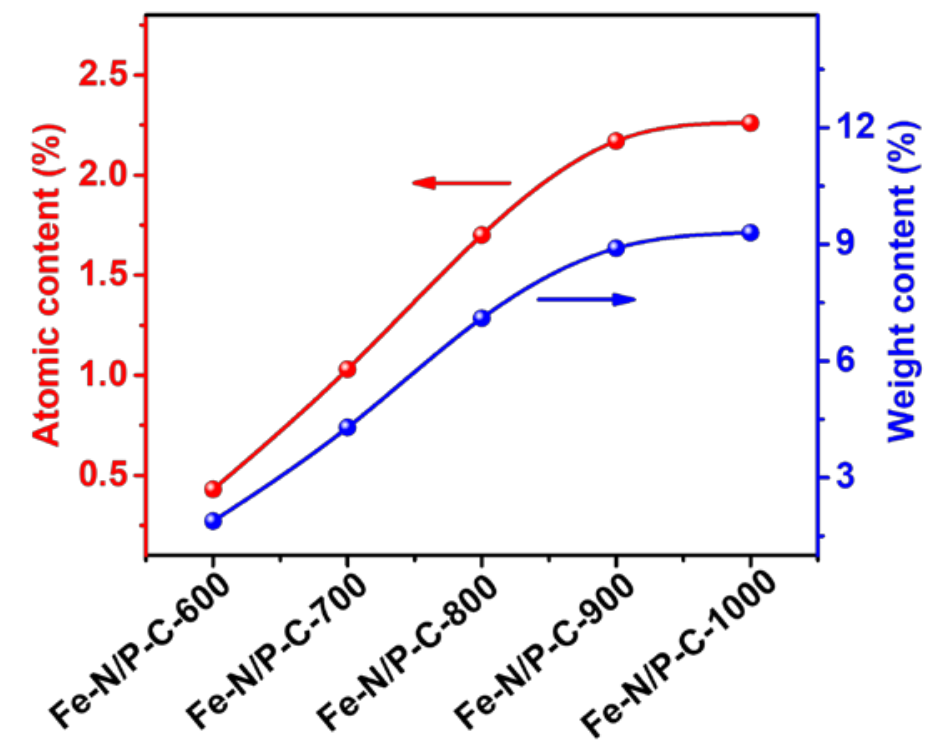

Figure S12. The atomic and weight contents of Fe for Fe-N/P-C samples prepared at different temperatures.

The contents of Fe in the Fe-N/P-C materials increase with the rising of the pyrolysis temperature. In the XRD patterns, diffraction peaks can be obtained after increasing the calcination temperature up to $800{ }^{\circ} \mathrm{C}$ (Figure S1), attributing to the formation of $\mathrm{Fe}_{2} \mathrm{P}$ nanoparticles during carbonization. Such Fe-based compounds wrapped with graphitic carbon layers exhibit strong durability and are can’t be easily etched by acid treatment. Notably, the intensity of the diffraction peaks indexed to $\mathrm{Fe}_{2} \mathrm{P}$ became more and more intense with the increase of the pyrolysis temperature, indicating the larger size and better crystallinity of $\mathrm{Fe}_{2} \mathrm{P}$ at higher temperature. This result matches well with the SEM, TEM, SAED, HRTEM results. 




Figure S13. Deconvoluted, high-resolution C 1s XPS spectra of Fe-N/P-C samples prepared at different temperatures. 


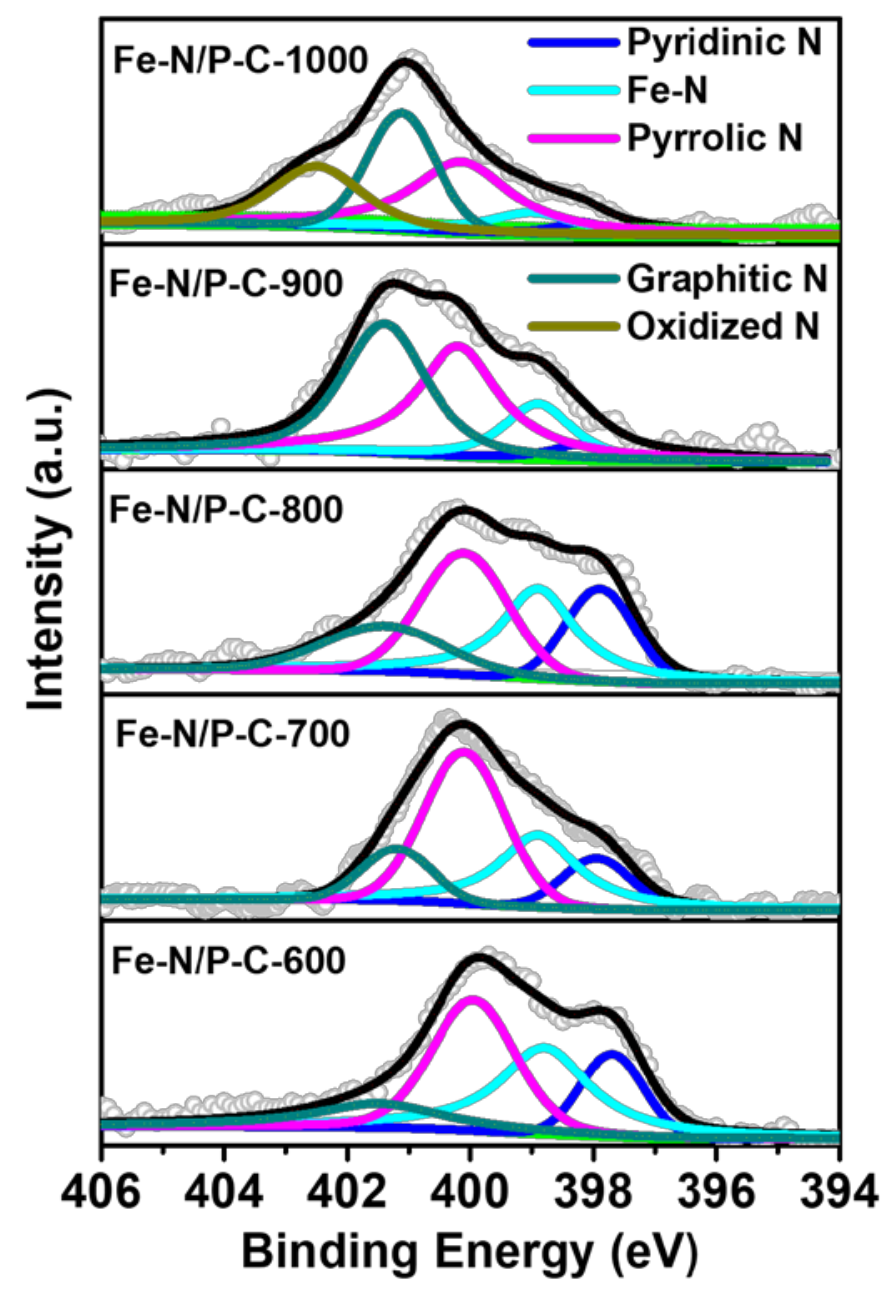

Figure S14. Deconvoluted, high-resolution N 1s XPS spectra of Fe-N/P-C samples prepared at different temperatures. 

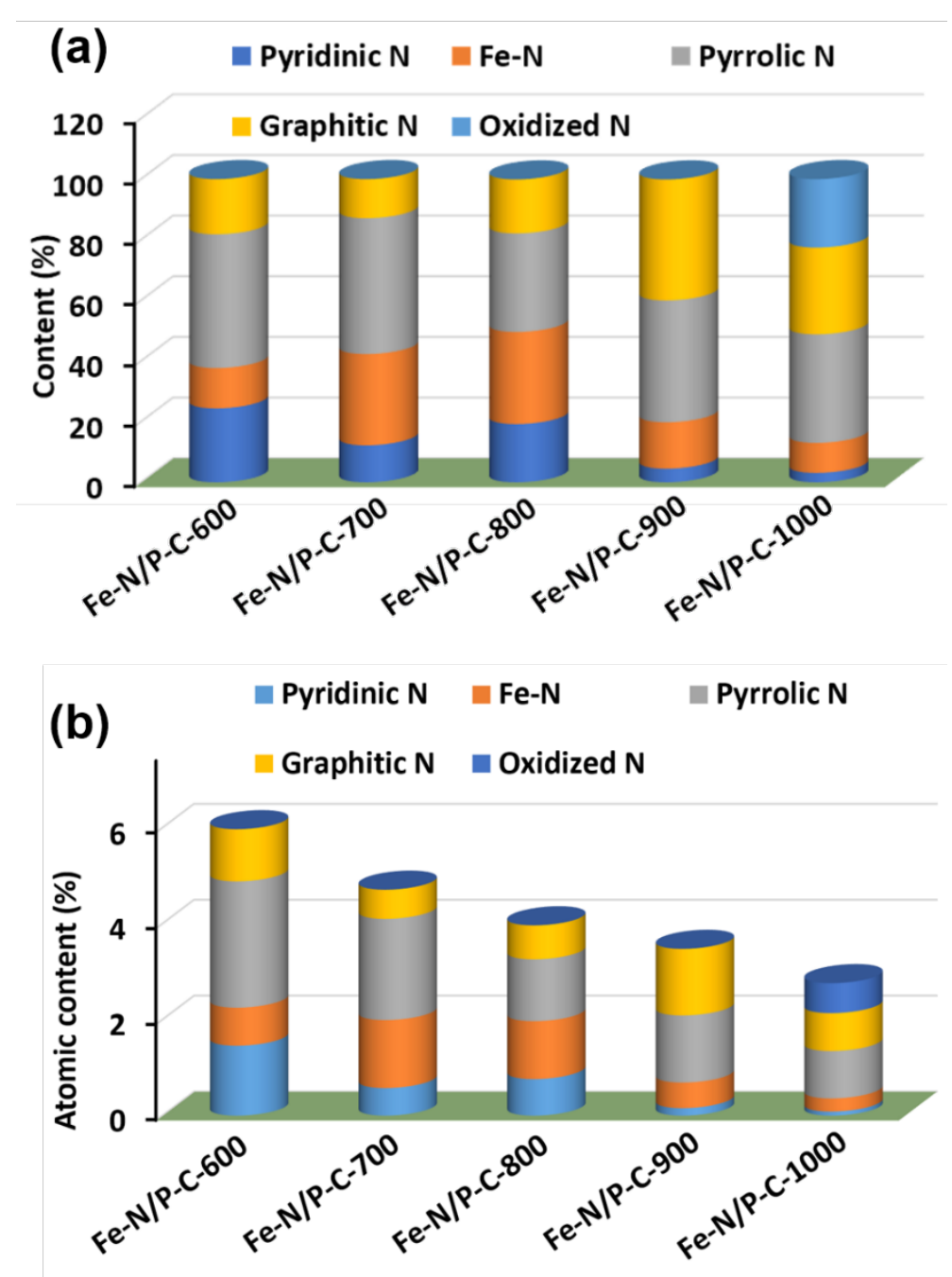

Figure S15. (a) Relative ratios and (b) atomic contents of the deconvoluted N species for Fe-N/P-C samples prepared at different temperatures calculated from the highresolution N 1s XPS spectra. 


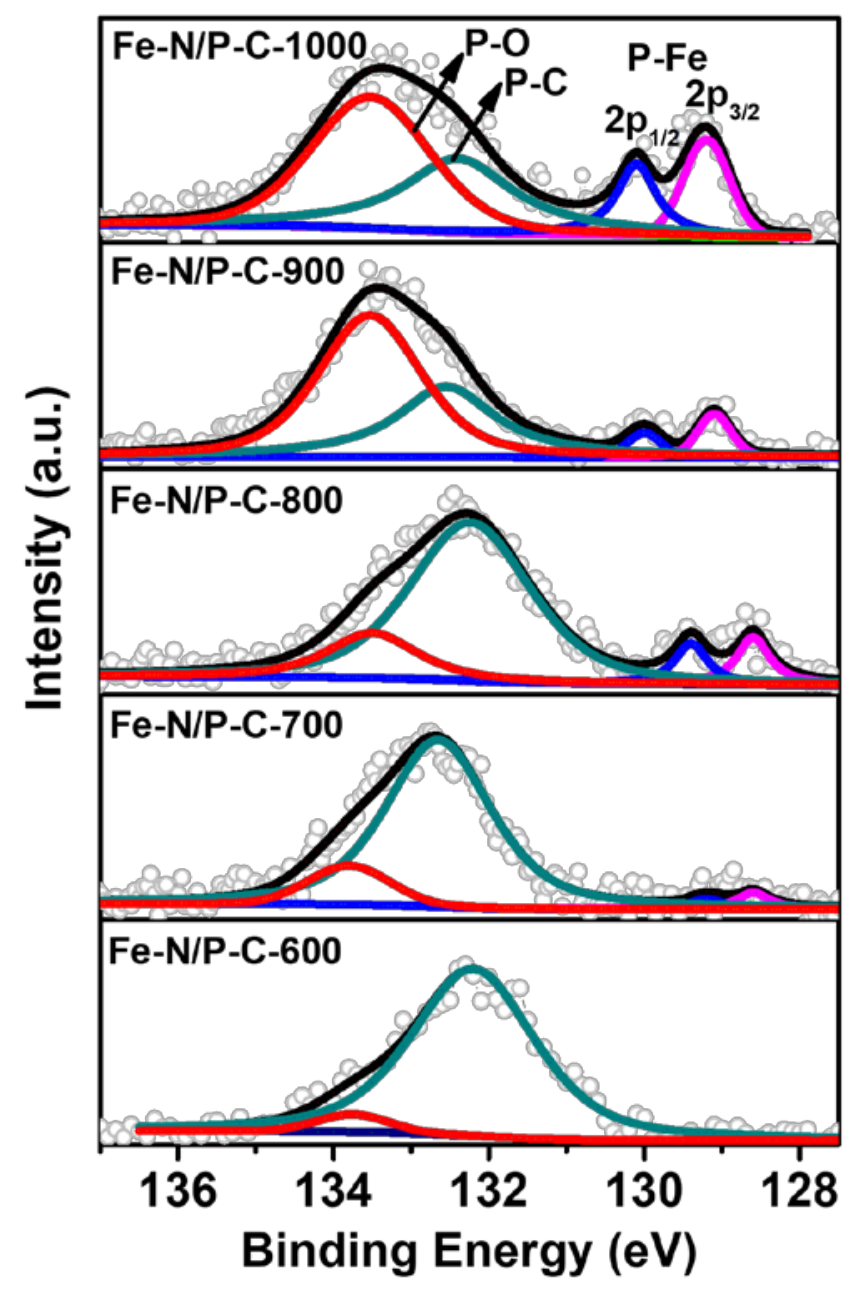

Figure S16. Deconvoluted, high-resolution P 2p XPS spectra of Fe-N/P-C samples prepared at different temperatures. 


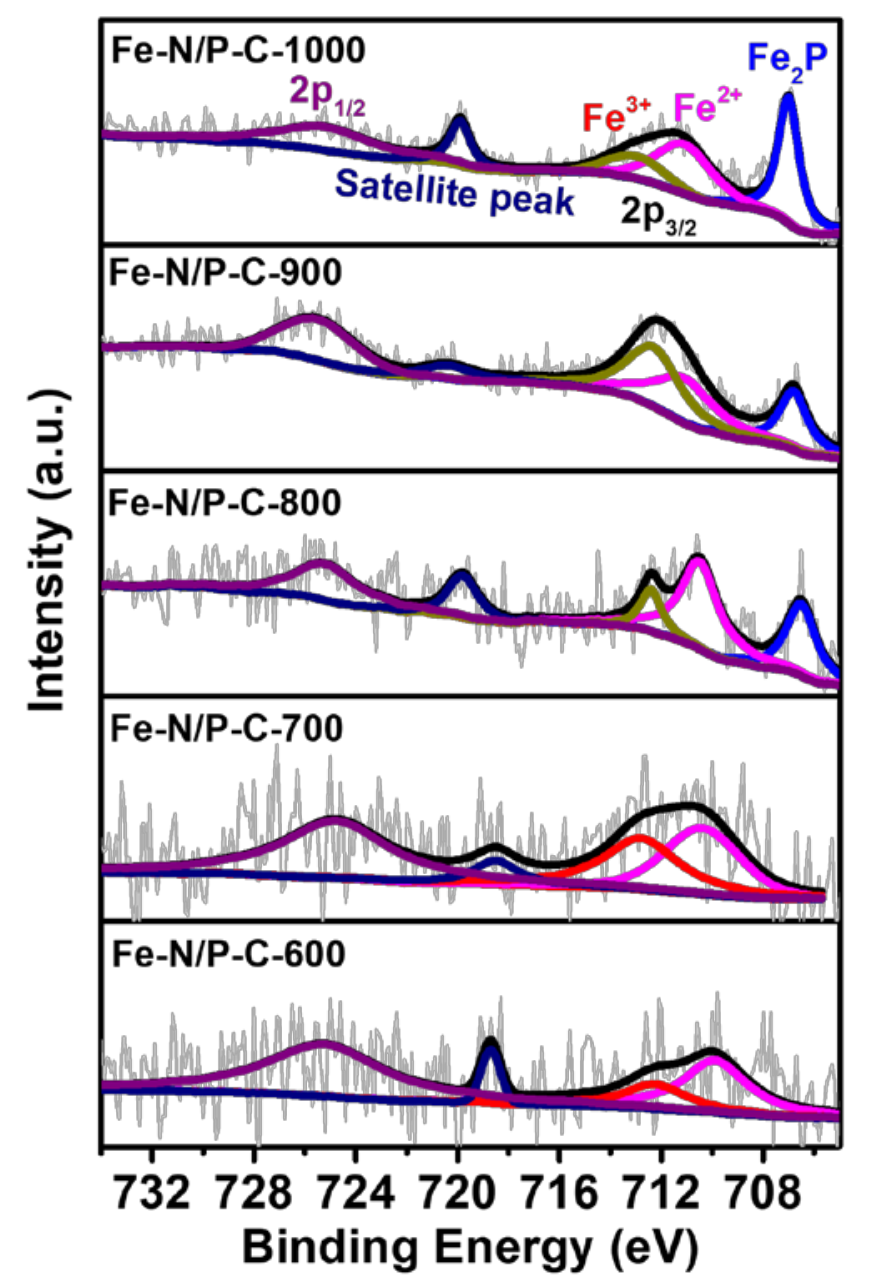

Figure S17. Deconvoluted, high-resolution Fe 2p XPS spectra of Fe-N/P-C samples prepared at different temperatures. The sharp peak located at $706.8 \mathrm{eV}$ matches well with the binding energy of $\mathrm{Fe}-\mathrm{P}$ bond, demonstrating the formation of $\mathrm{Fe}_{2} \mathrm{P}$ when the calcination temperature is higher than $800{ }^{\circ} \mathrm{C}$. This result matches well with the XRD, SEM, TEM, HRTEM data, and the elemental mapping analysis. 

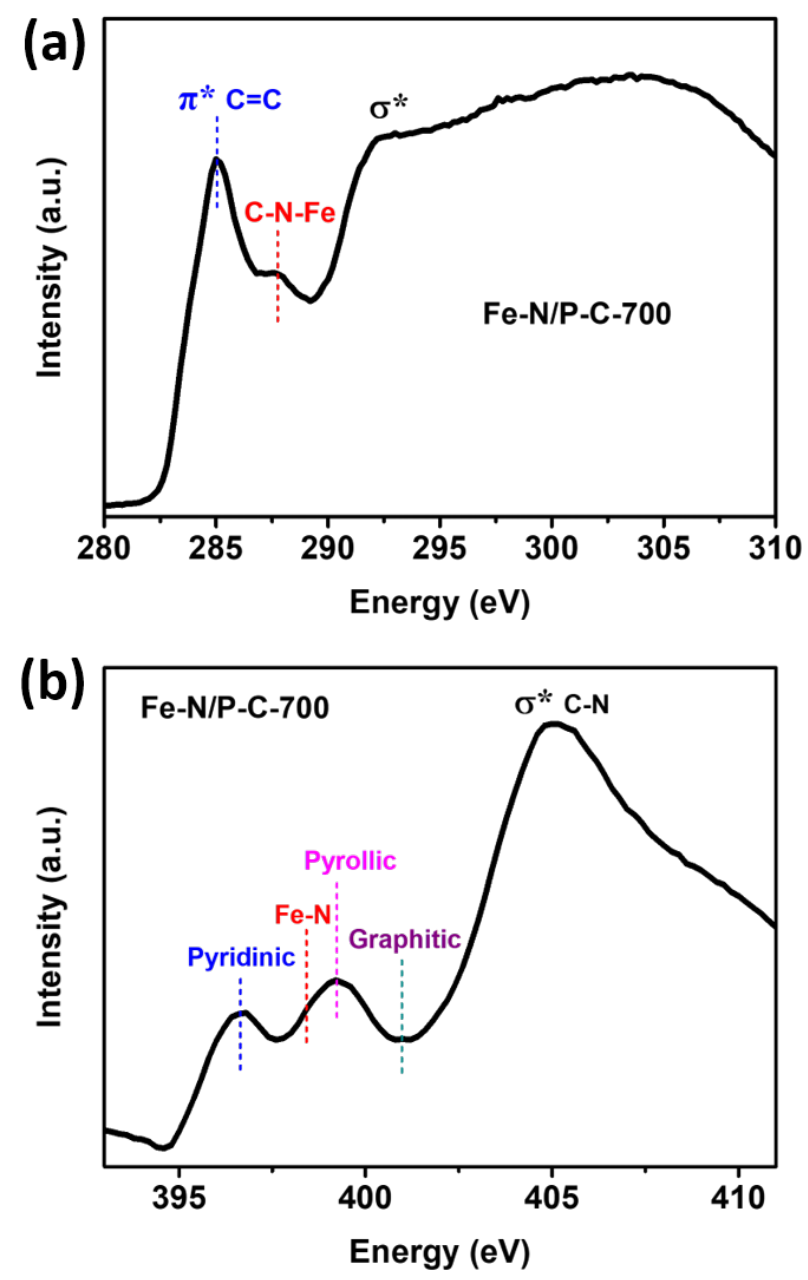

Figure S18. (a) C K-edge and (b) N K-edge XANES spectra of Fe-N/P-C-700. 

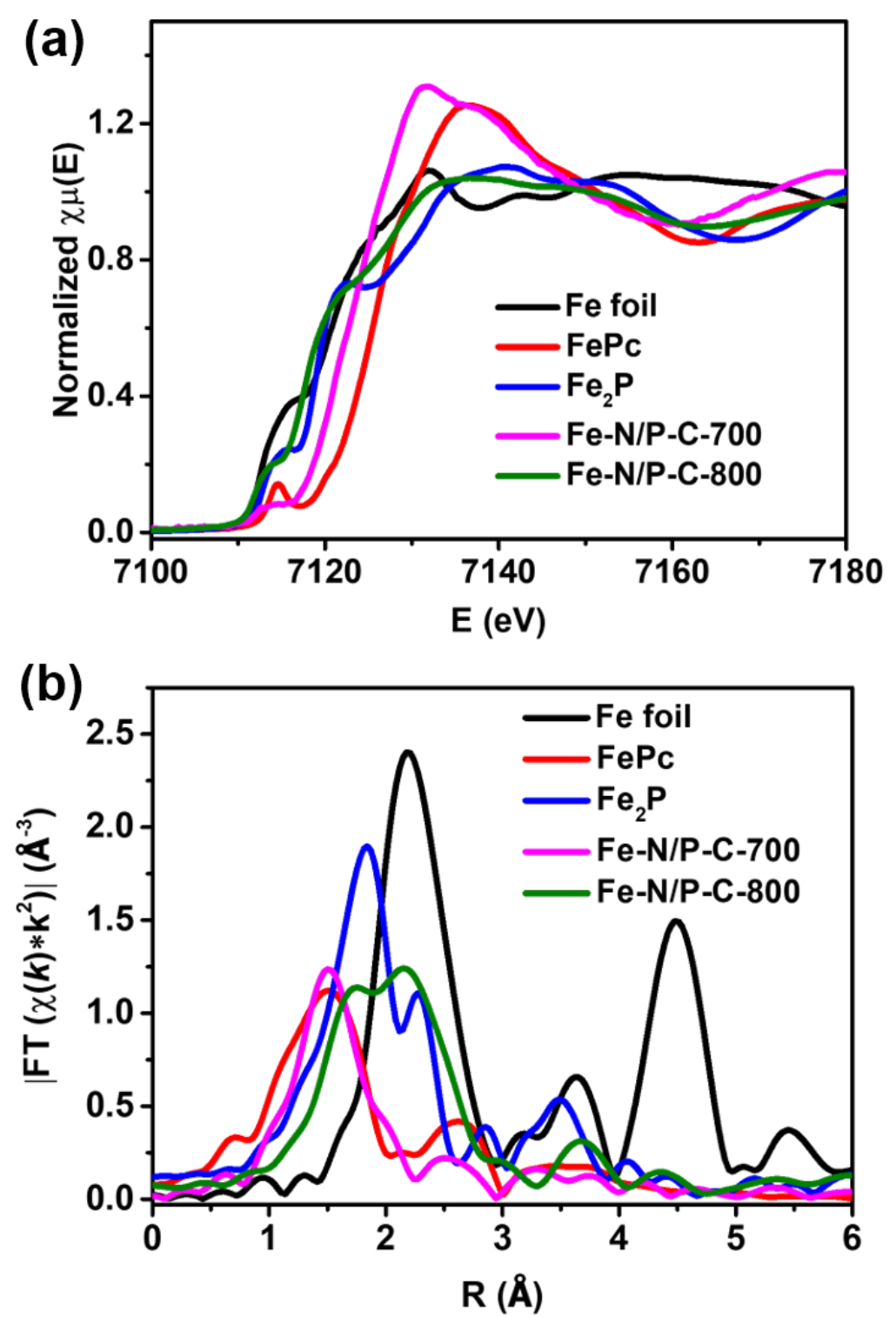

Figure S19. (a) Comparison of Fe K-edge XANES spectra of Fe-N/P-C-700, Fe-N/P$\mathrm{C}-800, \mathrm{FePc}, \mathrm{Fe}_{2} \mathrm{P}$, and iron foil. (b) Fourier transform of the EXAFS spectra of FeN/P-C-700, Fe-N/P-C-800, FePc, $\mathrm{Fe}_{2} \mathrm{P}$, and iron foil. 


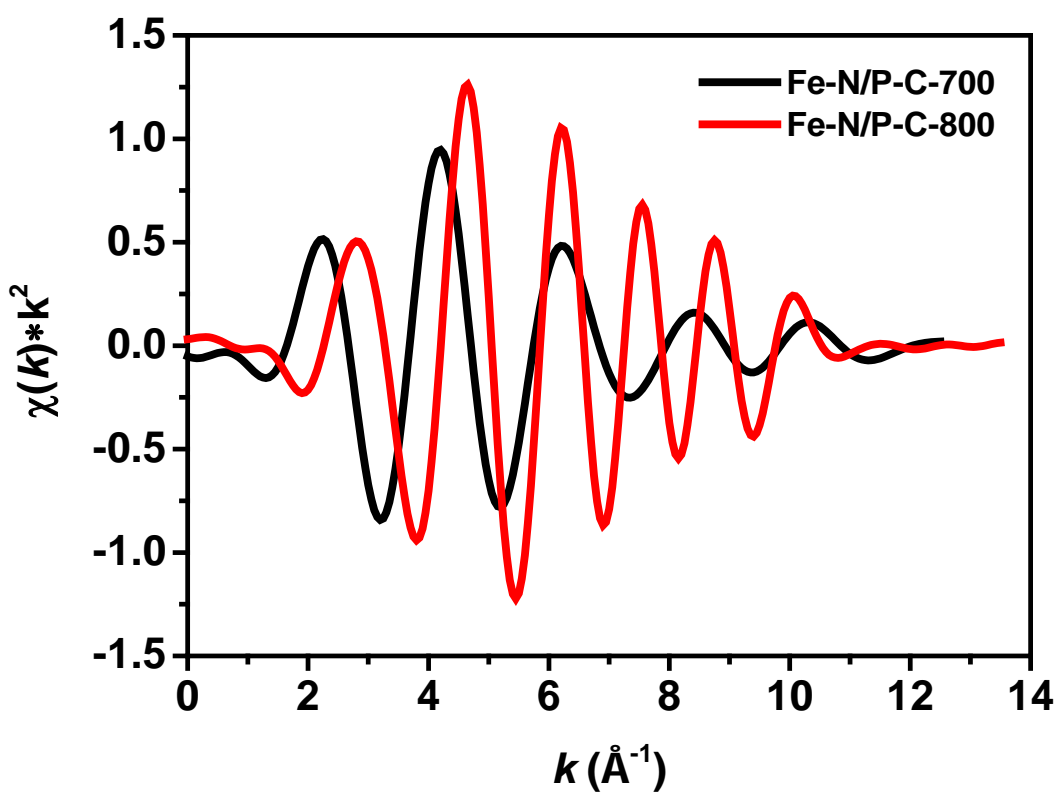

Figure S20. Fe K-edge extended XAFS oscillation function $k^{2}[\chi(k)]$ of Fe-N/P-C-700 and Fe-N/P-C-800, $k$ is the wave vector, $\chi(k)=$ oscillation as a function of photoelectron wavenumber. The Fe K-edge fine structure oscillations for Fe-N/P-C-700 exhibit remarkable differences in contrast to the Fe-N/P-C-800, indicating different atomic arrangements. 



Figure S21. The corresponding EXAFS fitting curves of Fe-N/P-C-800 at (a) $k$ space and (b) $R$ space, respectively. 

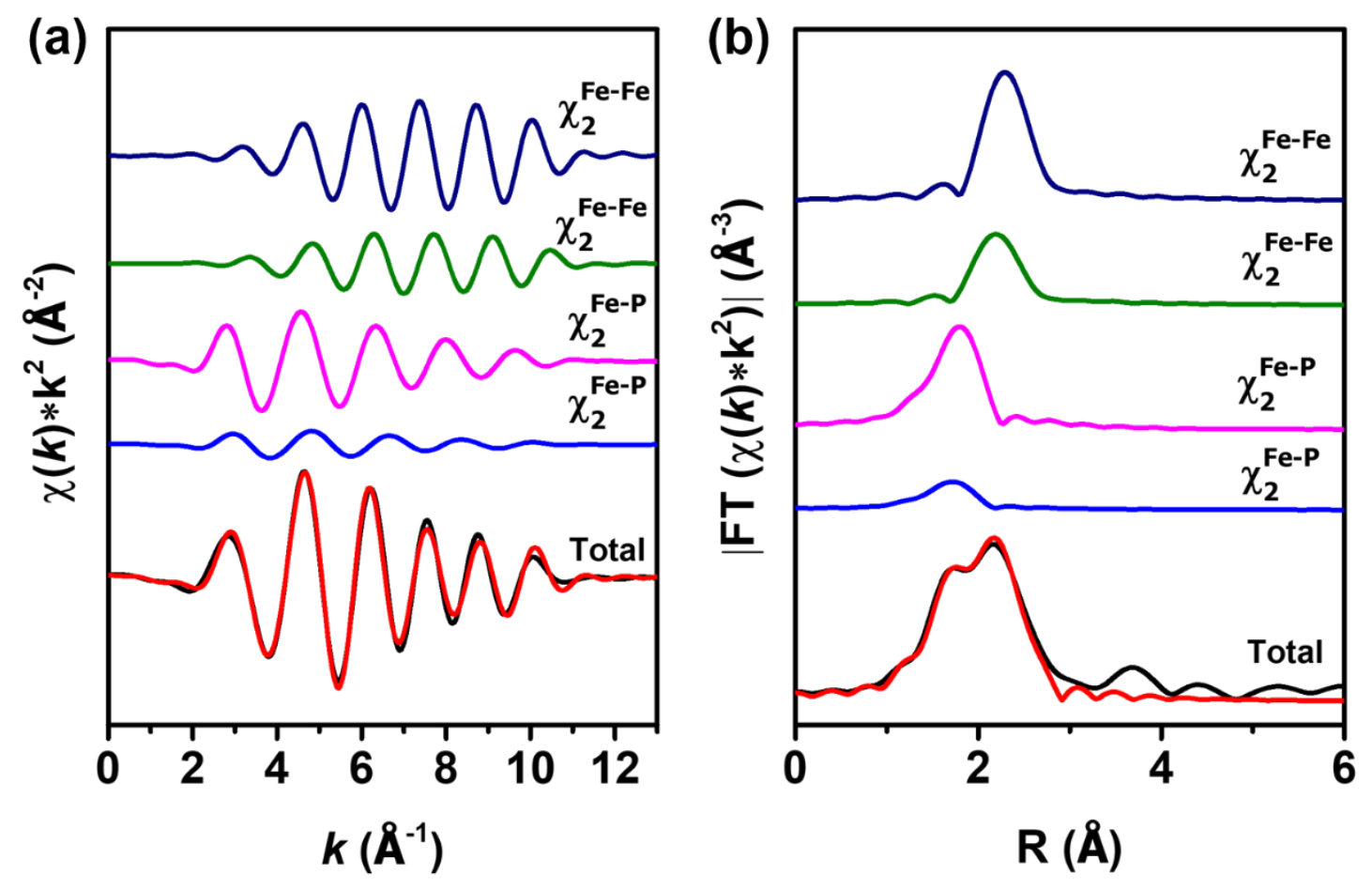

Figure S22. EXAFS analysis of Fe-N/P-C-800 at (a) $k$ and (b) $R$ space, respectively. Curves from top to bottom are the Fe-N, and Fe-P two-body backscattering signals $\chi_{2}$ included in the fit and the total signal (red line) superimposed on the experimental signal (black line). The measured and calculated spectra show excellent agreement. 




Figure S23. Room-temperature ${ }^{57} \mathrm{Fe}$ Mössbauer spectrum of Fe-N/P-C-700. 

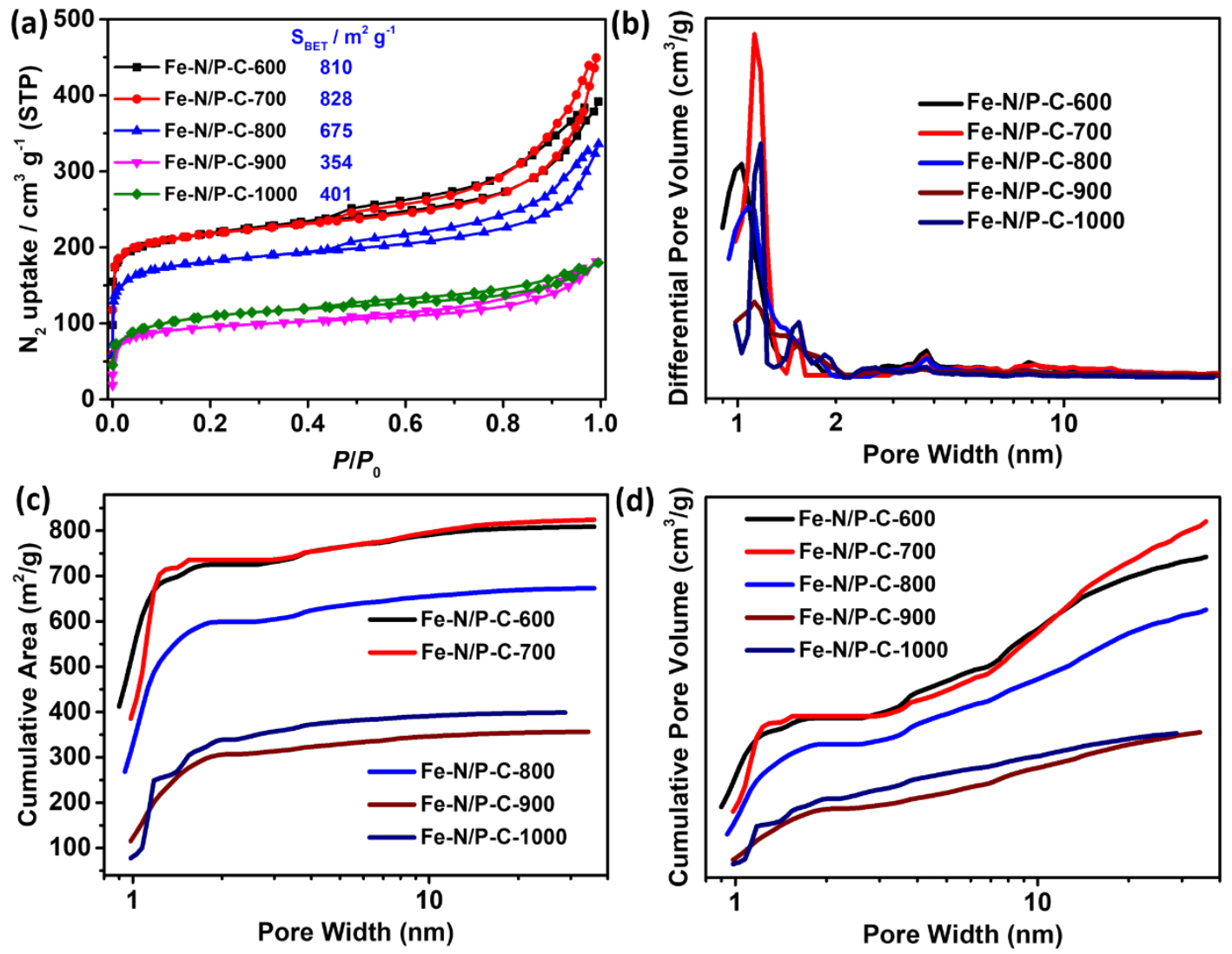

Figure S24. (a) $\mathrm{N}_{2}$ adsorption and desorption isotherms, (b) detailed pore size distribution, (c) cumulated surface areas, and (d) pore volumes as function of the pore width for the Fe-N/P-C- $X$ samples prepared at different temperatures. The pore size distribution was calculated by nonlinear density functional theory (NL-DFT) by assuming a slit pore geometry for micropores and a cylindrical geometry pore for mesopores, respectively. 


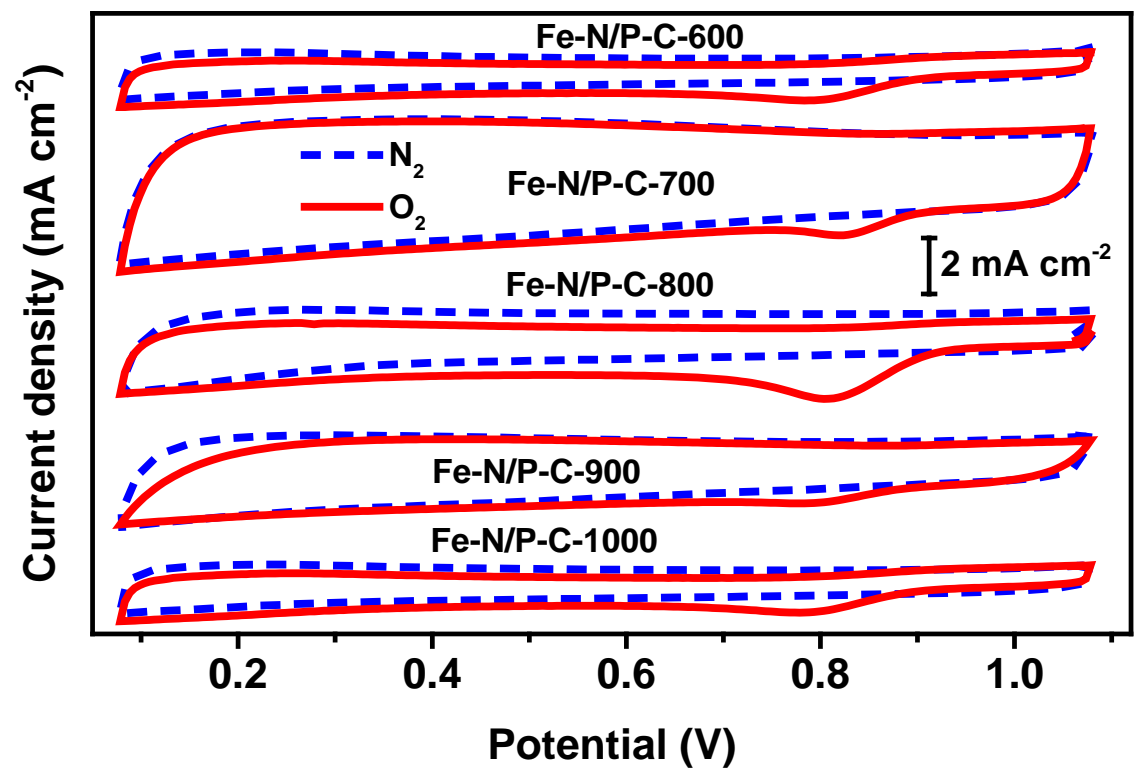

Figure S25. Cyclic voltammograms of Fe-N/P-C samples in $\mathrm{O}_{2}$ (solid lines) and $\mathrm{N}_{2}$ (dashed lines) saturated $0.1 \mathrm{M} \mathrm{KOH}$ solution. The curves are vertically displaced with respect to each other for a better comparison. 

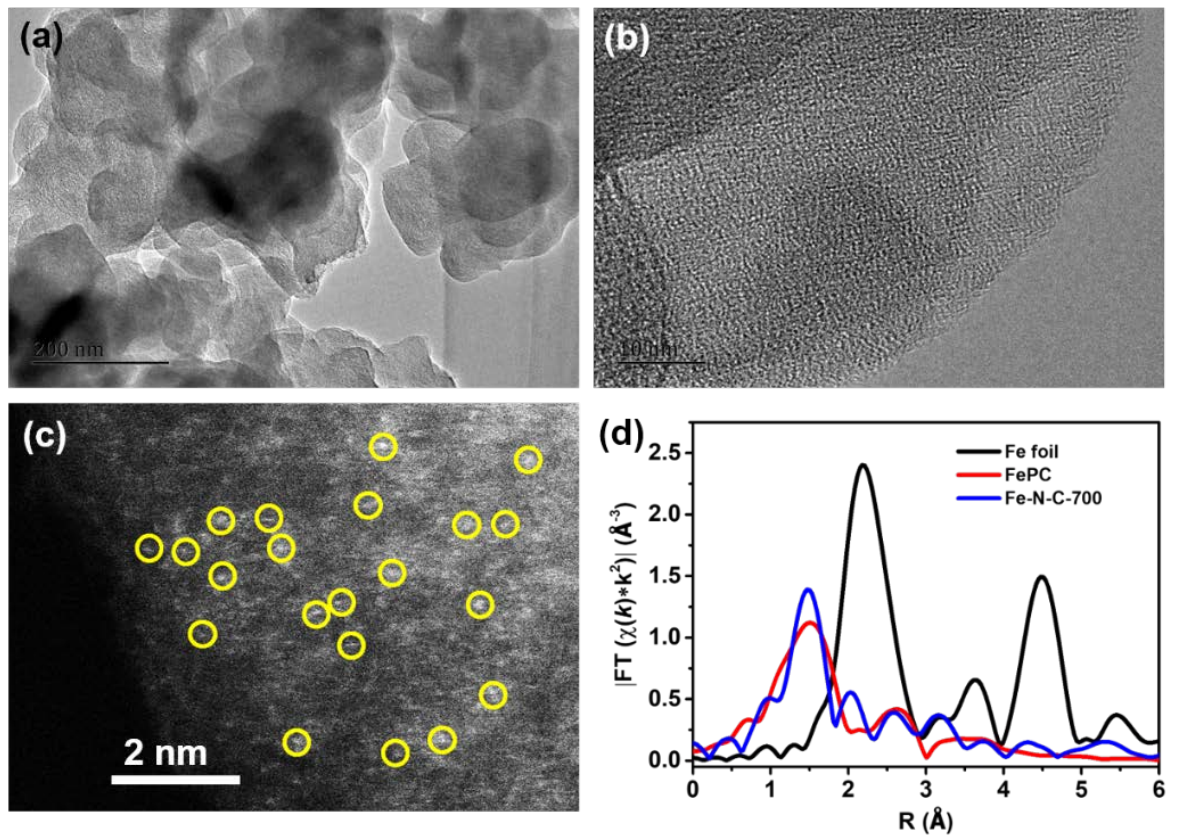

Figure S26. (a) TEM and (b) HRTEM images of Fe-N-C-700. (c) Aberration corrected HAADF-STEM image of Fe-N-C-700, partial single Fe atoms are circled in yellow. (d) Fourier transform of the EXAFS spectra of iron foil, FePc, and Fe-N-C-700. 

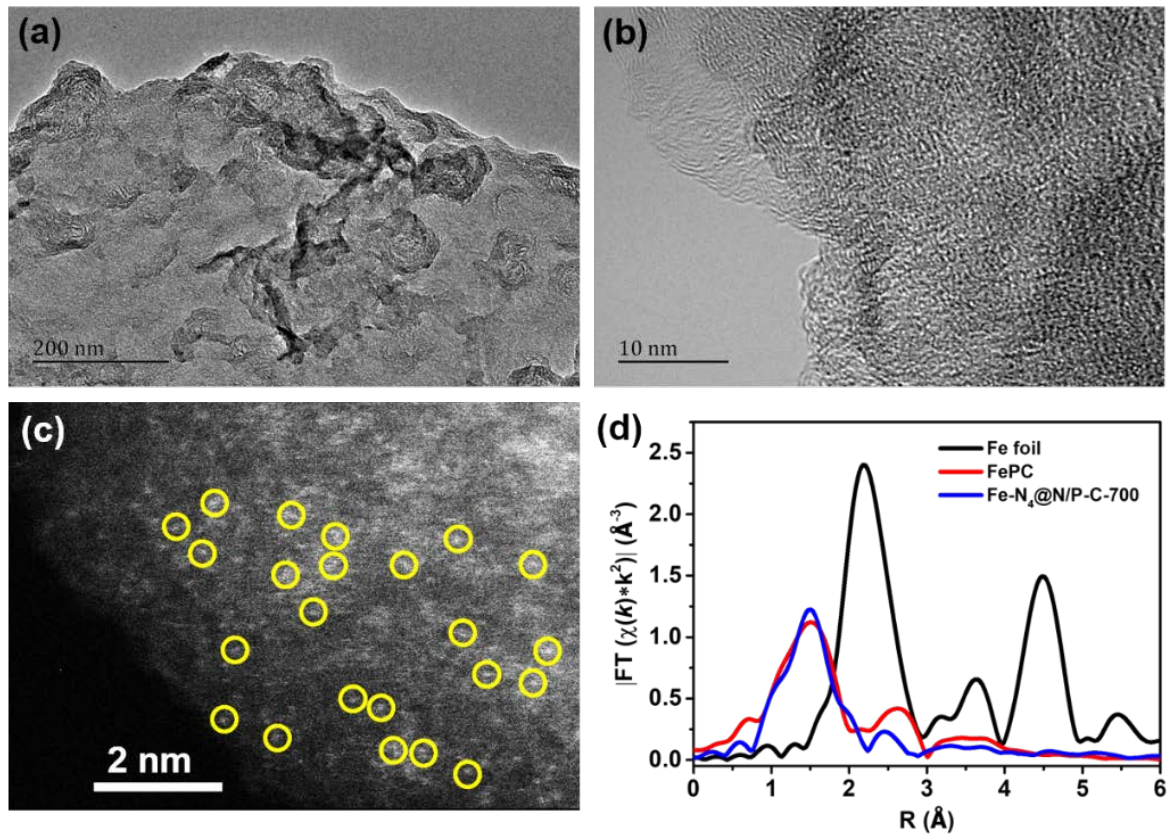

Figure S27. (a) TEM and (b) HRTEM images of Fe-N 4 @N/P-C-700. (c) Aberration corrected HAADF-STEM image of Fe-N 4 @N/P-C-700, partial single Fe atoms are circled in yellow. (d) Fourier transform of the EXAFS spectra of iron foil, FePc, and Fe-N4@N/P-C-700. 


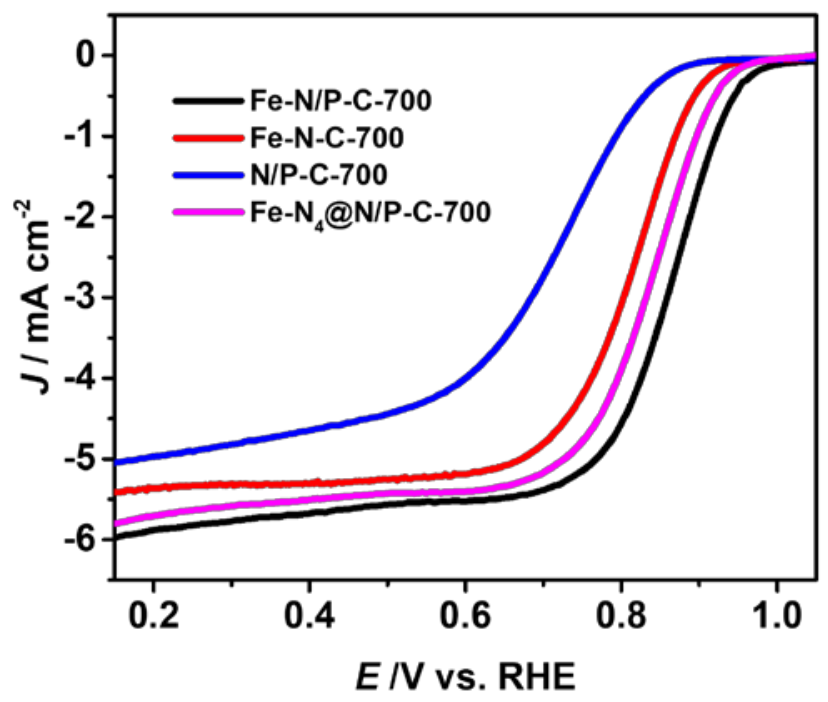

Figure S28. ORR polarization curves of Fe-N/P-C-700, Fe-N-C-700, N/P-C-700, and Fe-N $4 @$ N/P-C-700 catalysts at a rotating speed of 1600 rpm in $0.1 \mathrm{M} \mathrm{KOH}$ solution. 

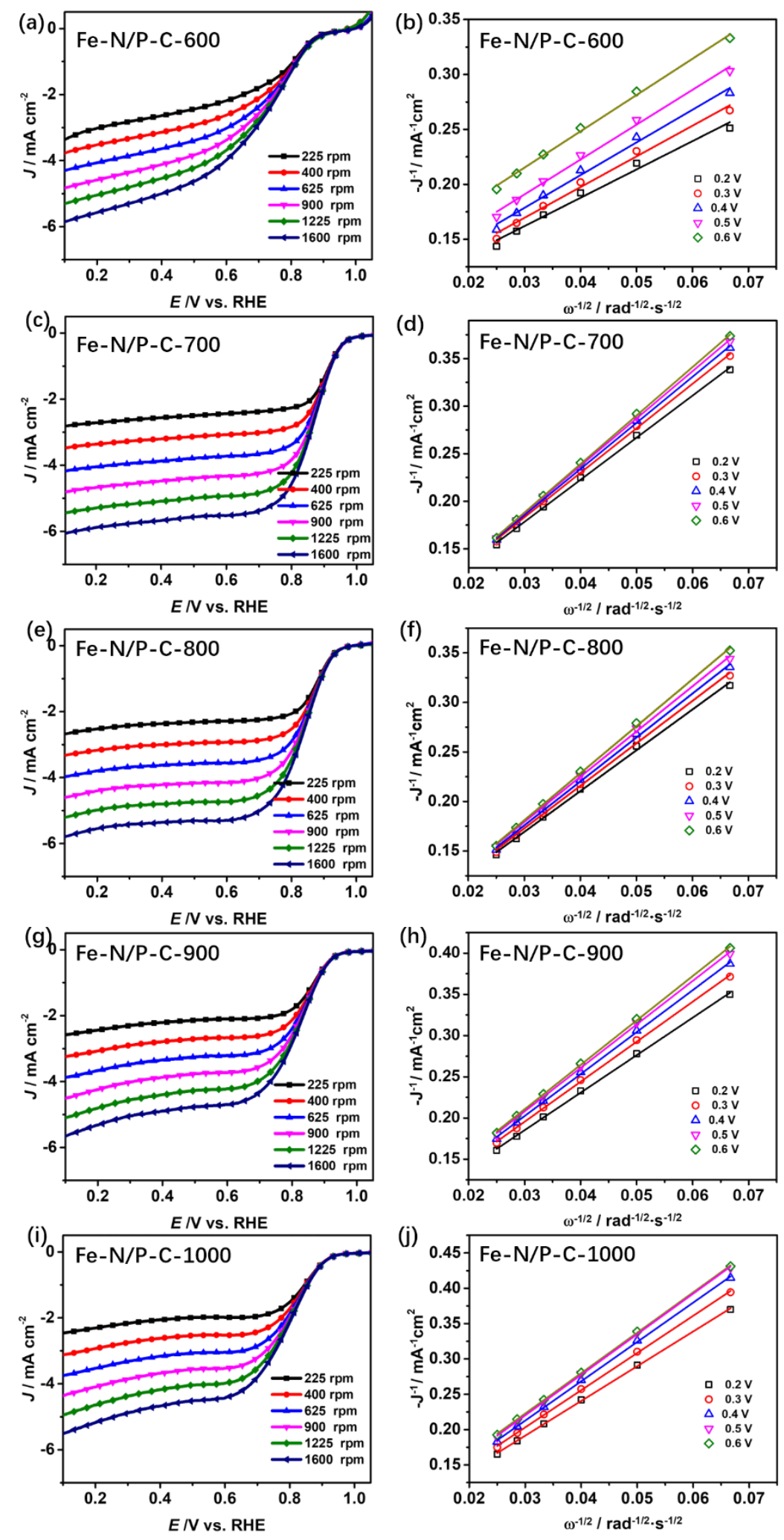

Figure S29. LSV curves at various rotation rates and corresponding Koutecky - Levich plots of Fe-N/P-C samples. 


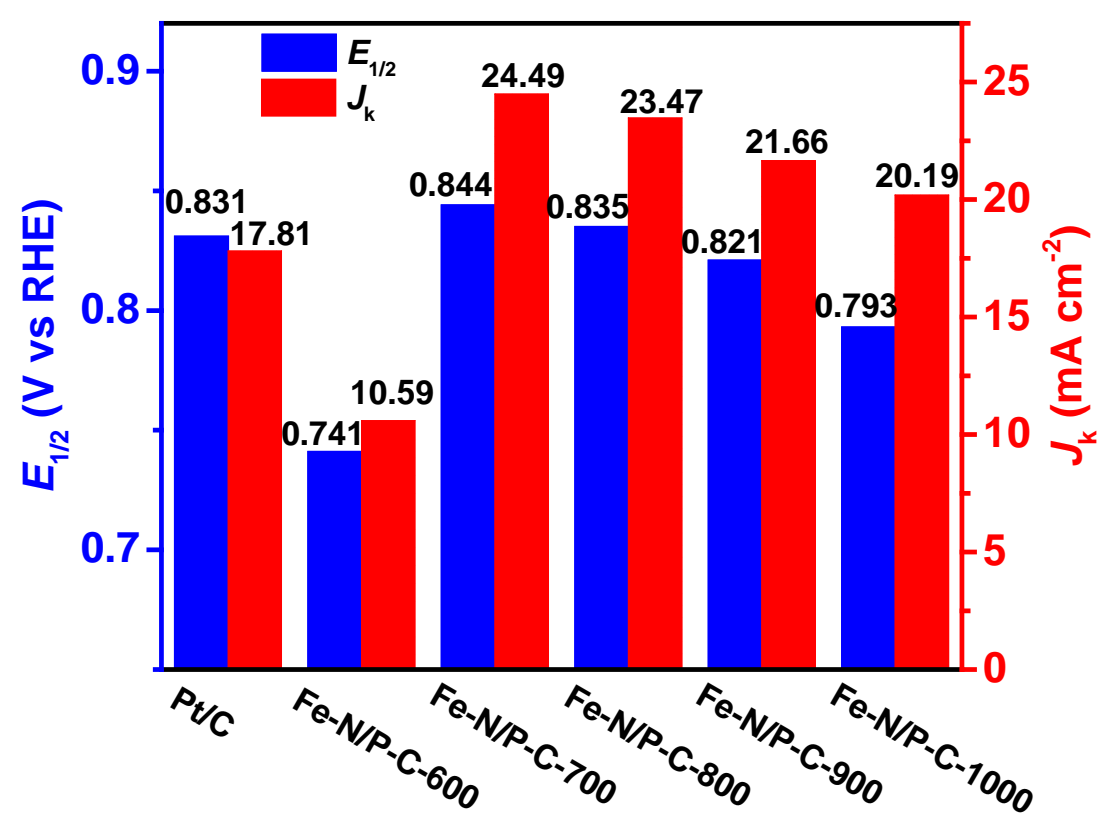

Figure S30. Comparison of $E_{1 / 2}$ and $J_{\mathrm{k}}$ for various catalysts in $0.1 \mathrm{M} \mathrm{KOH}$.

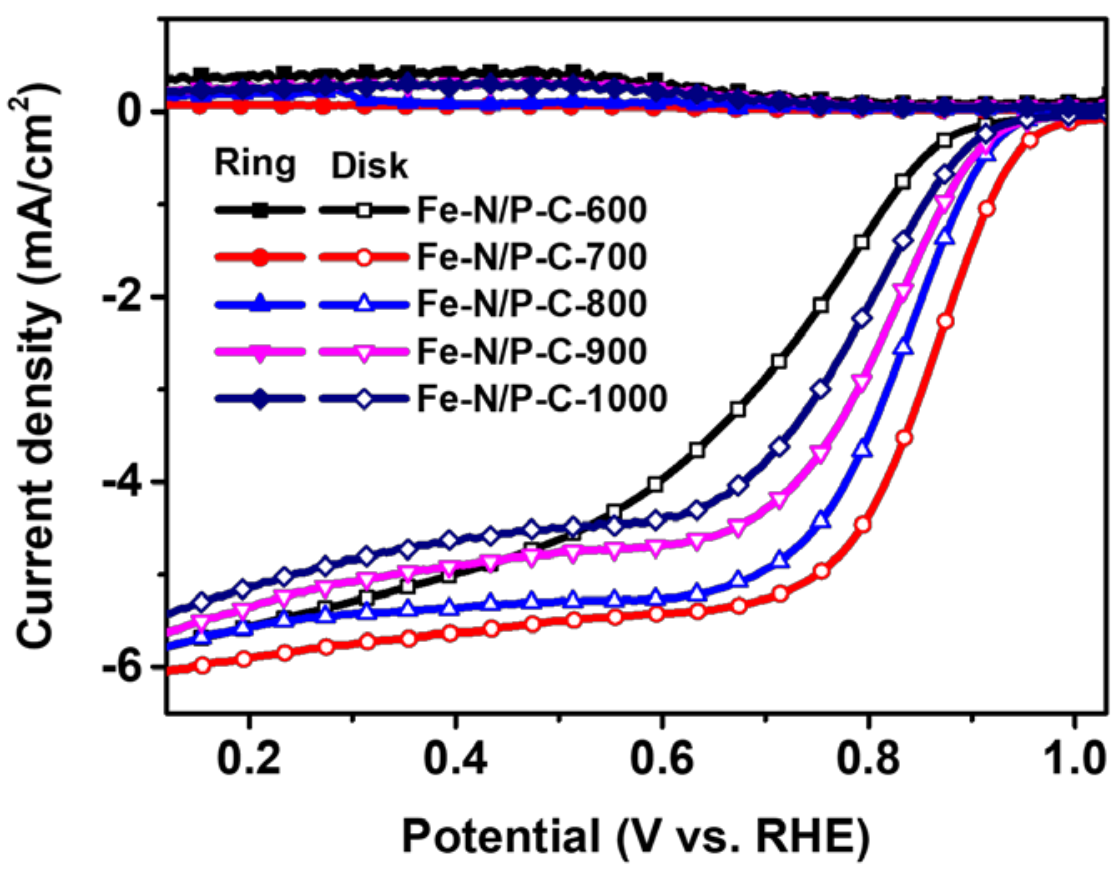

Figure S31. RRDE curves for Fe-N/P-C catalysts prepared at different temperatures $\left(600,700,800,900\right.$, and $\left.1000{ }^{\circ} \mathrm{C}\right)$. 




Figure S32. Electron transfer number ( $n$ ) (top) and $\mathrm{H}_{2} \mathrm{O}_{2}$ yield (bottom) vs. potential for Fe-N/P-C catalysts prepared at different temperatures (600, 700, 800, 900, and $\left.1000{ }^{\circ} \mathrm{C}\right)$. 


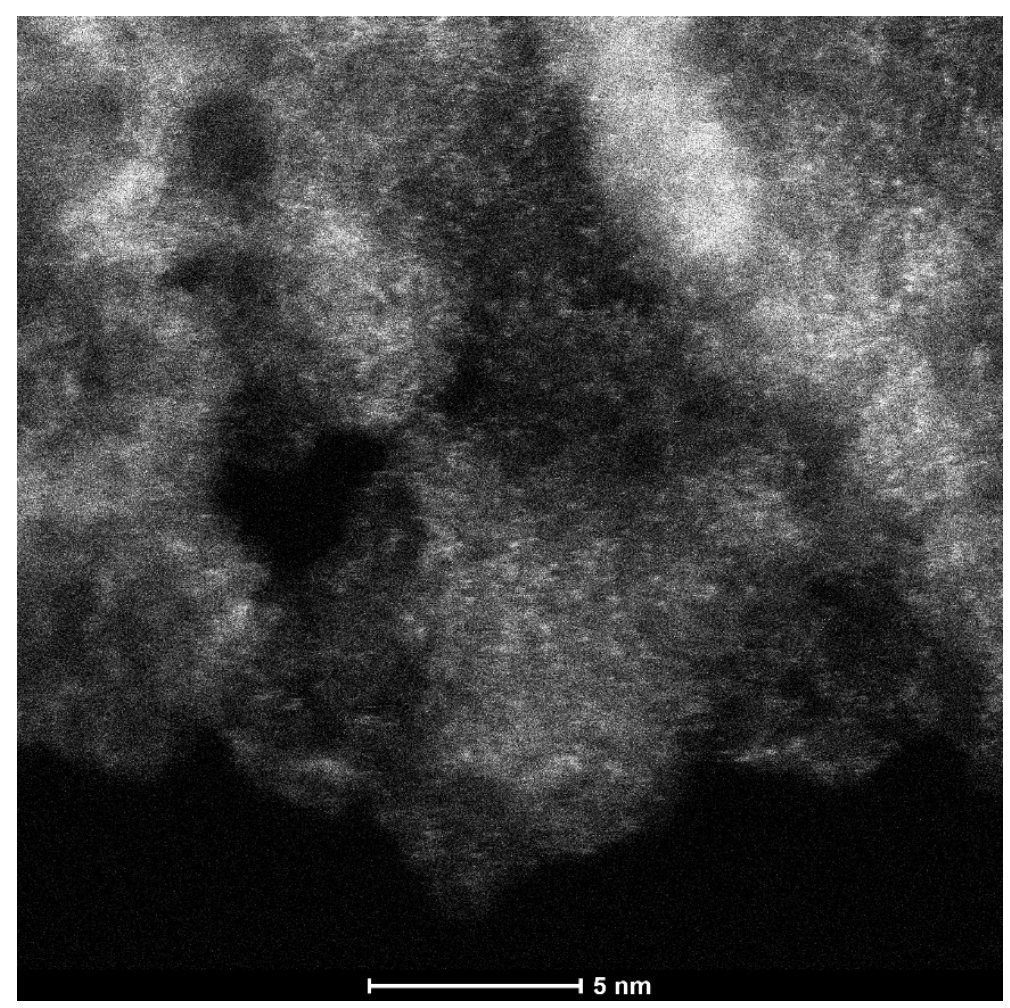

Figure S33. Aberration-corrected atomic-resolution HAADF-STEM image of Fe-N/PC-700 after durability measurement. 

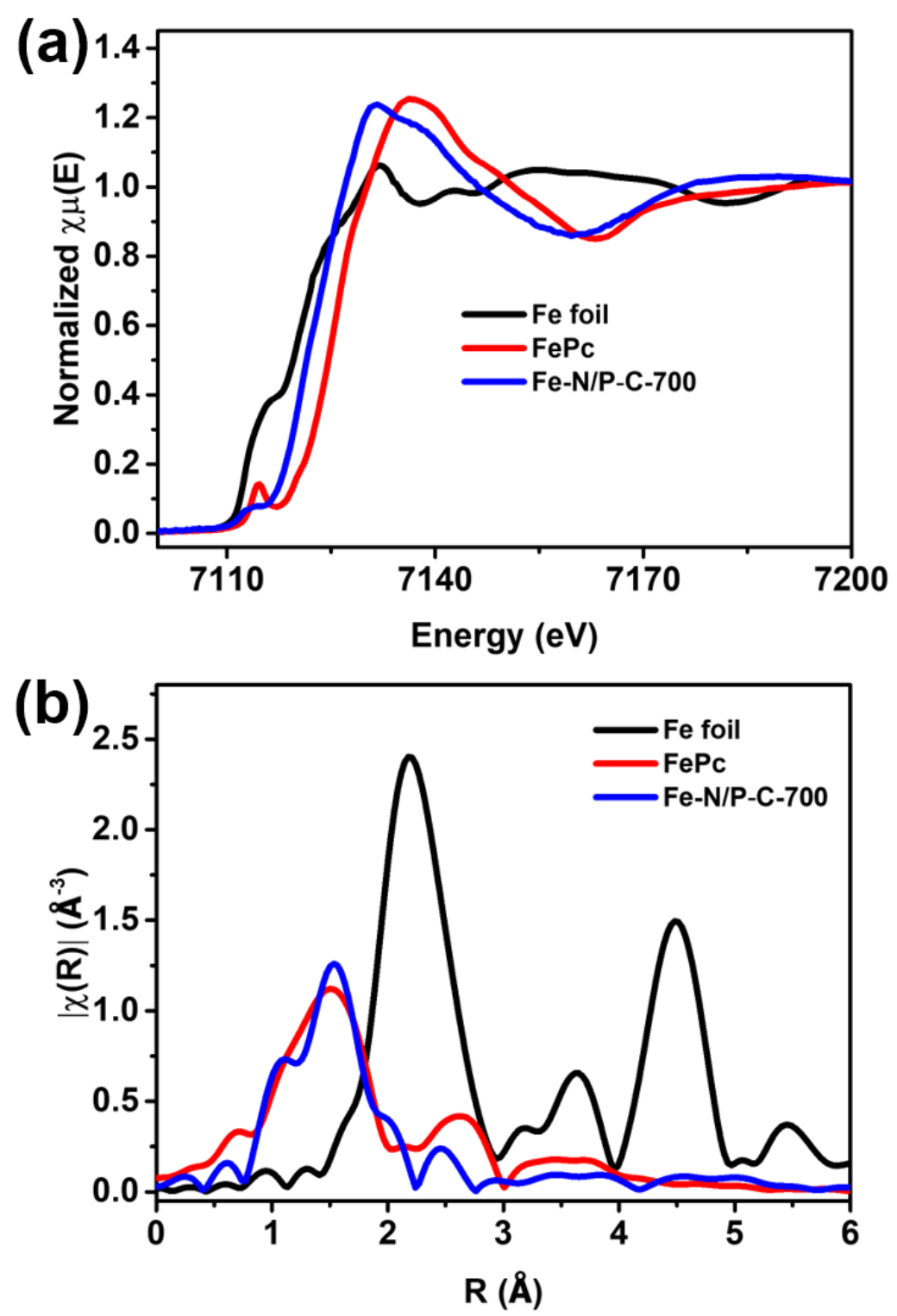

Figure S34. Comparison of (a) Fe K-edge XANES spectra and (b) corresponding Fourier transform of the EXAFS spectra of Fe-N/P-C-700 after durability measurement, FePc, and iron foil. 




Figure S35. Steady-state ORR polarization curves of Fe-N/P-C-700 recorded in $\mathrm{O}_{2}$ saturated $0.1 \mathrm{M} \mathrm{KOH}$ with or without poisoning by $0.01 \mathrm{M} \mathrm{SCN}^{-}$, and one collected after removing $\mathrm{SCN}^{-}$. 

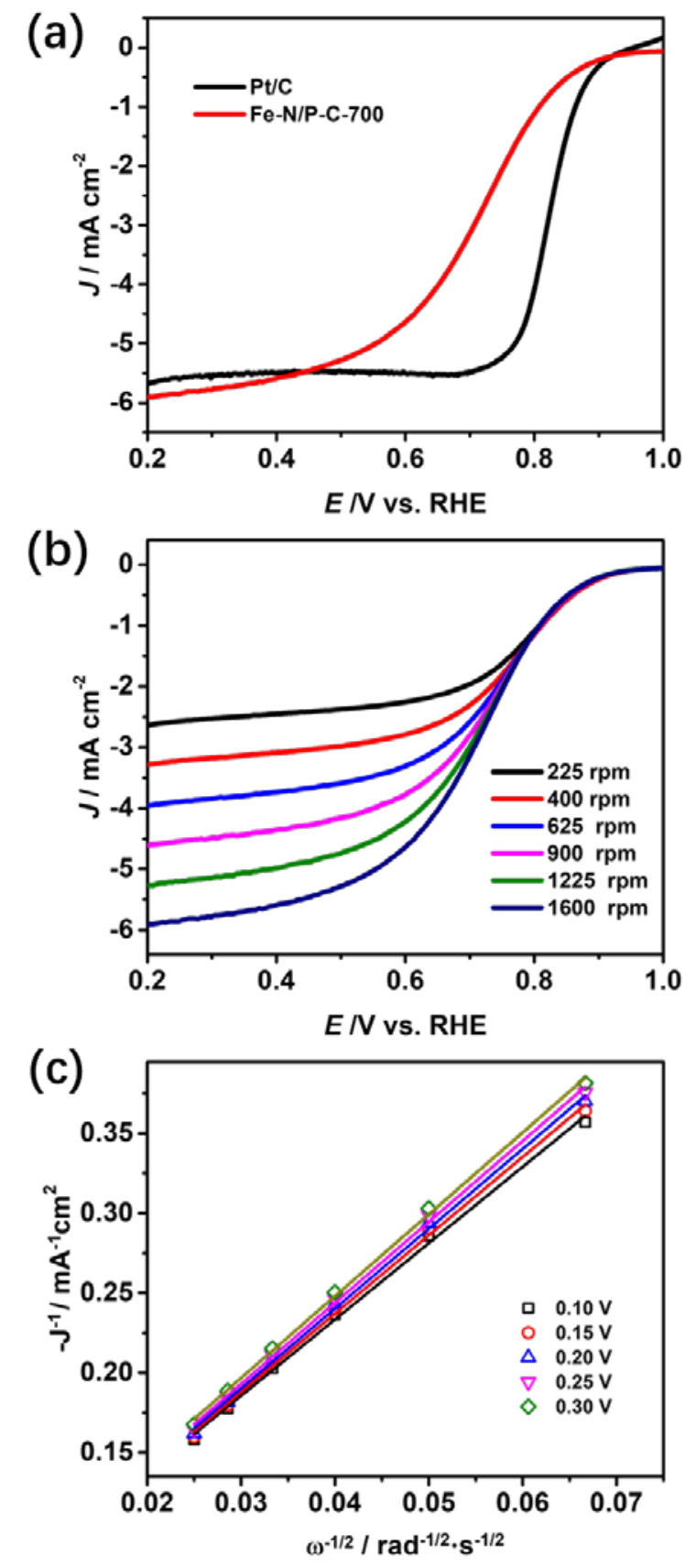

Figure S36. ORR performance of Fe-N/P-C-700 and commercial Pt/C in $\mathrm{O}_{2}$-saturated $0.1 \mathrm{M} \mathrm{HClO}_{4}$. (a) LSV curves of Fe-N/P-C-700 and Pt/C at a rotating speed of 1600 rpm. (b) LSV curves of Fe-N/P-C-700 for various rotation rates. (c) The corresponding K-L plots at different potentials. 

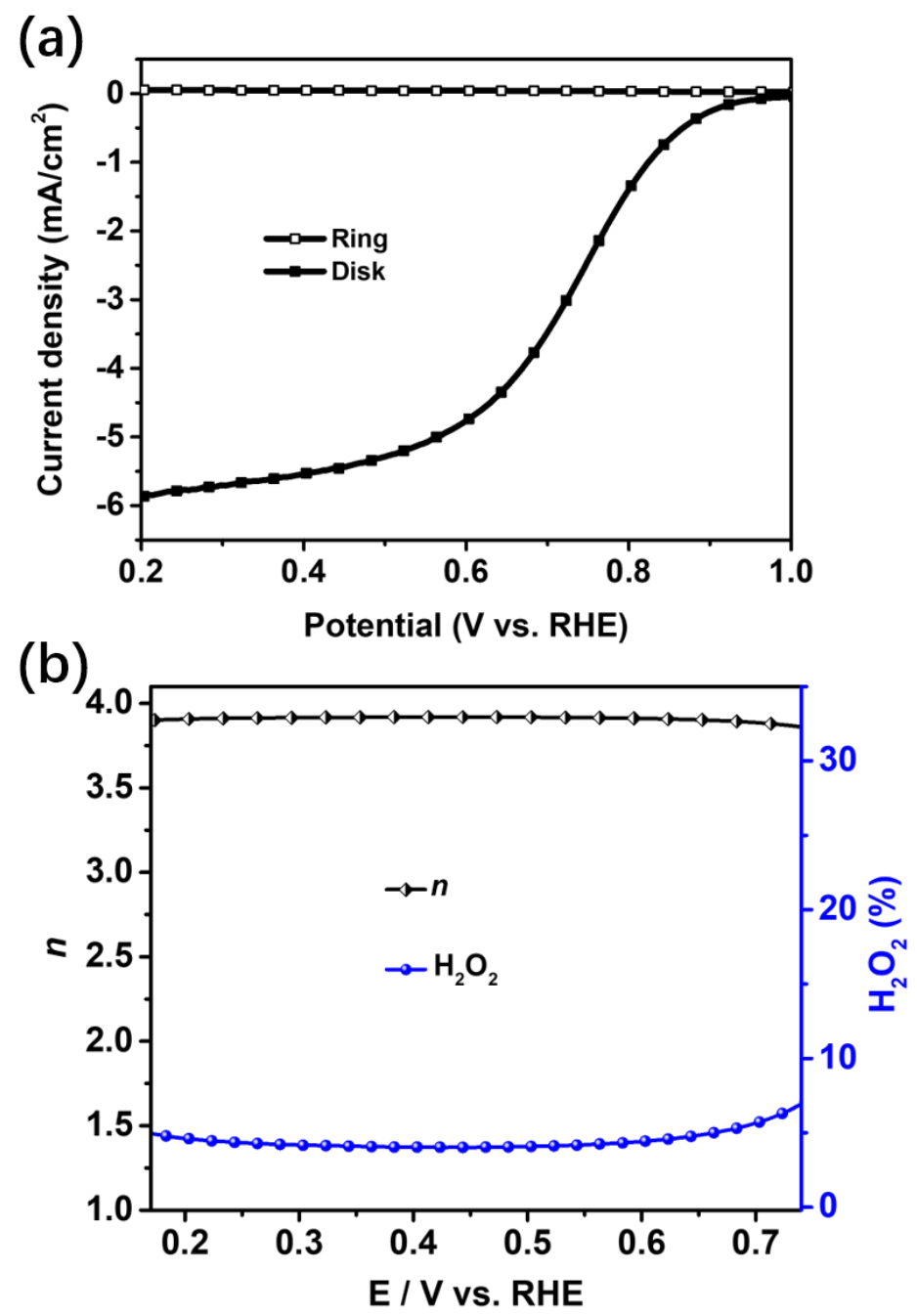

Figure S37. (a) RRDE curves and (b) electron transfer number ( $n$ ) (top) and $\mathrm{H}_{2} \mathrm{O}_{2}$ yield (bottom) vs potential for Fe-N/P-C-700 in $\mathrm{O}_{2}$-saturated $0.1 \mathrm{M} \mathrm{HClO}_{4}$. 

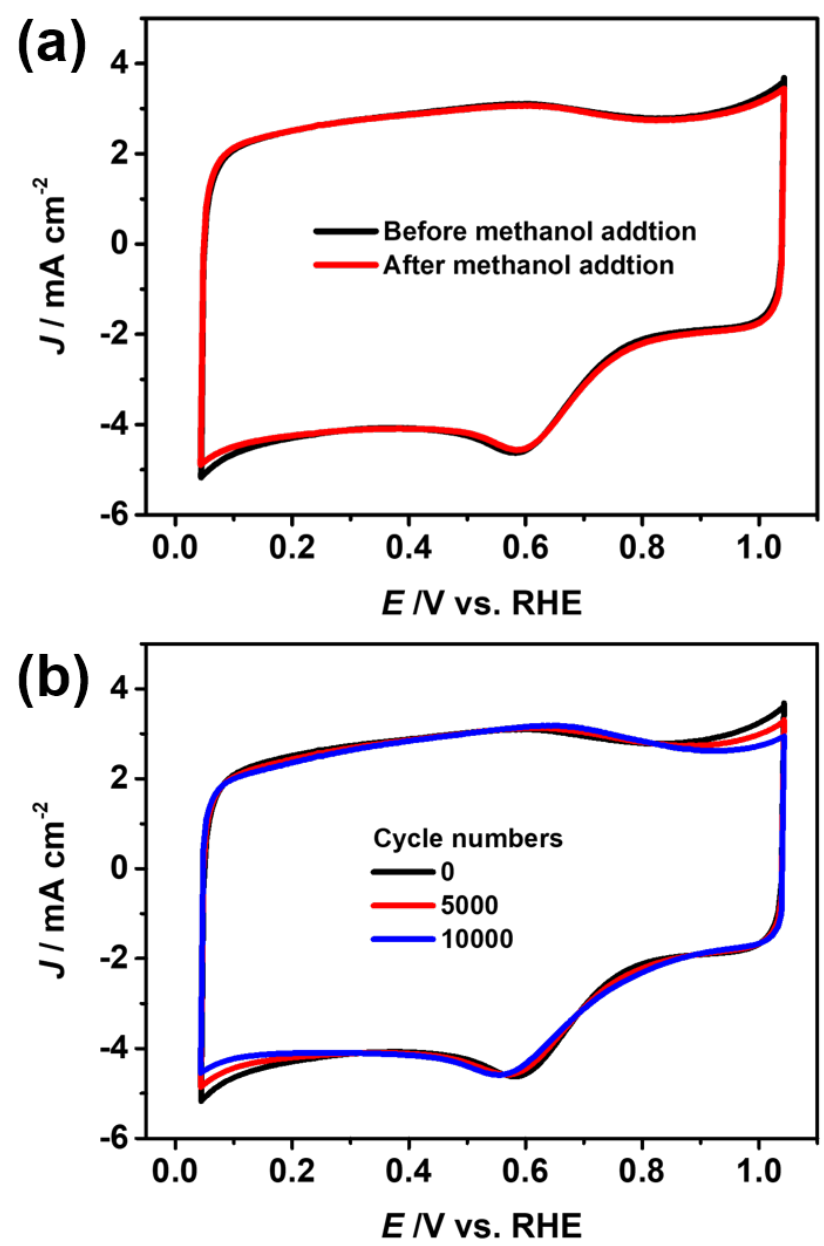

Figure S38. $\mathrm{CV}$ curves of Fe-N/P-C-700 in $\mathrm{O}_{2}$-saturated $0.1 \mathrm{M} \mathrm{HClO}_{4}$ electrolyte (a) without and with $3 \mathrm{M} \mathrm{CH}_{3} \mathrm{OH}$, and (b) before and after 5000 and 10000 cycles. 

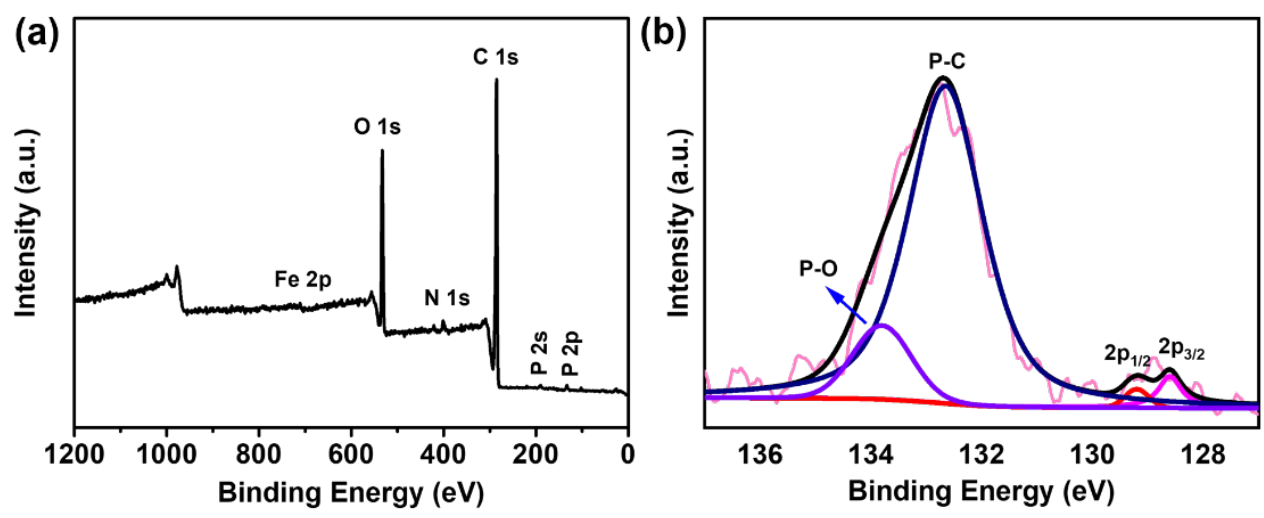

Figure S39. (a) The survey XPS spectrum and (b) the deconvoluted, high-resolution P 2p XPS spectra of Fe-N/P-C-700 after durability measurement. 


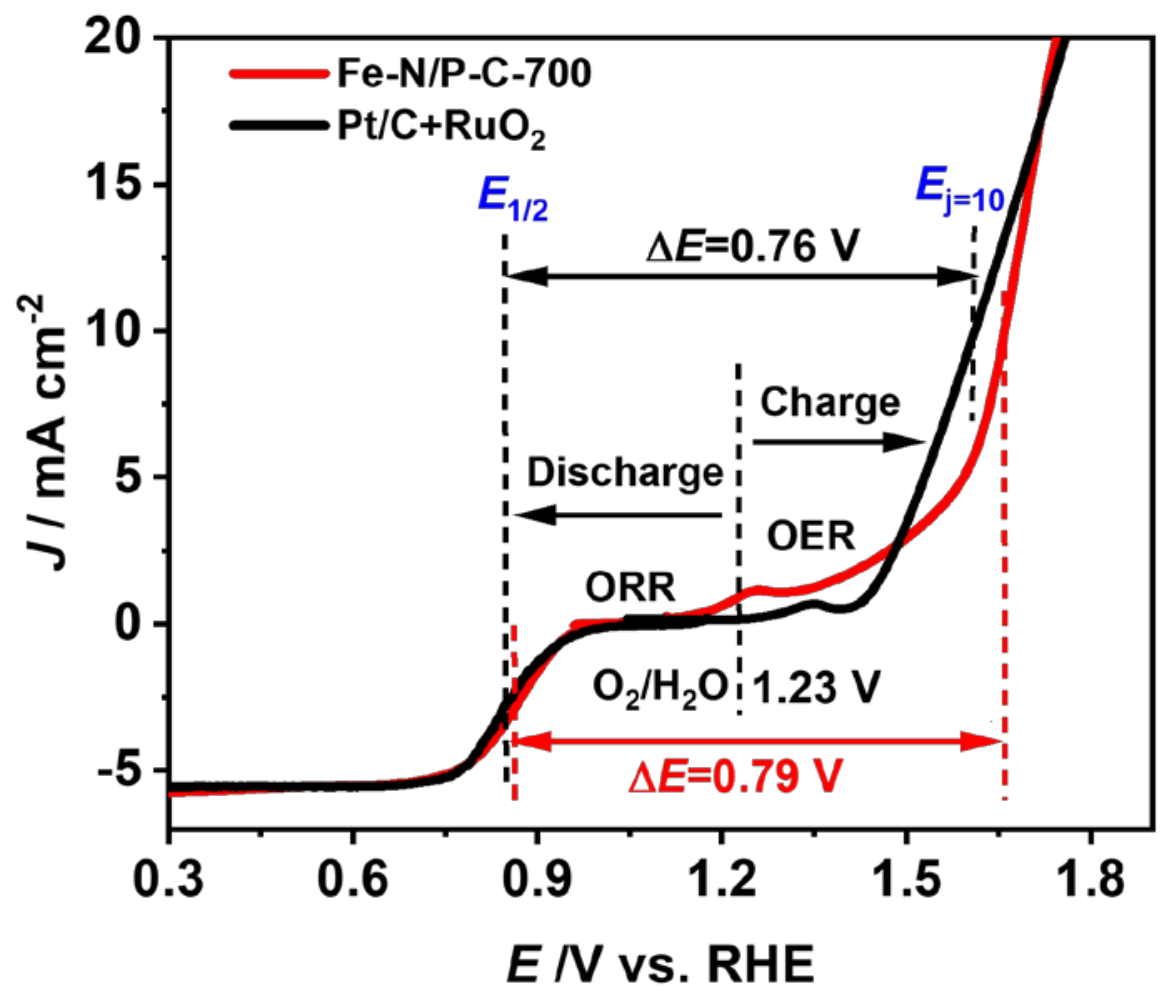

Figure S40. Overall polarization plots (1600 rpm) in the ORR and OER potential windowpane for Fe-N/P-C-700, commercial Pt/C, and $\mathrm{RuO}_{2}$ catalysts; the inset depicts the overall electrocatalytic oxygen performance $\left(\Delta E=E_{\mathrm{j}=10}-E_{1 / 2}\right)$. 


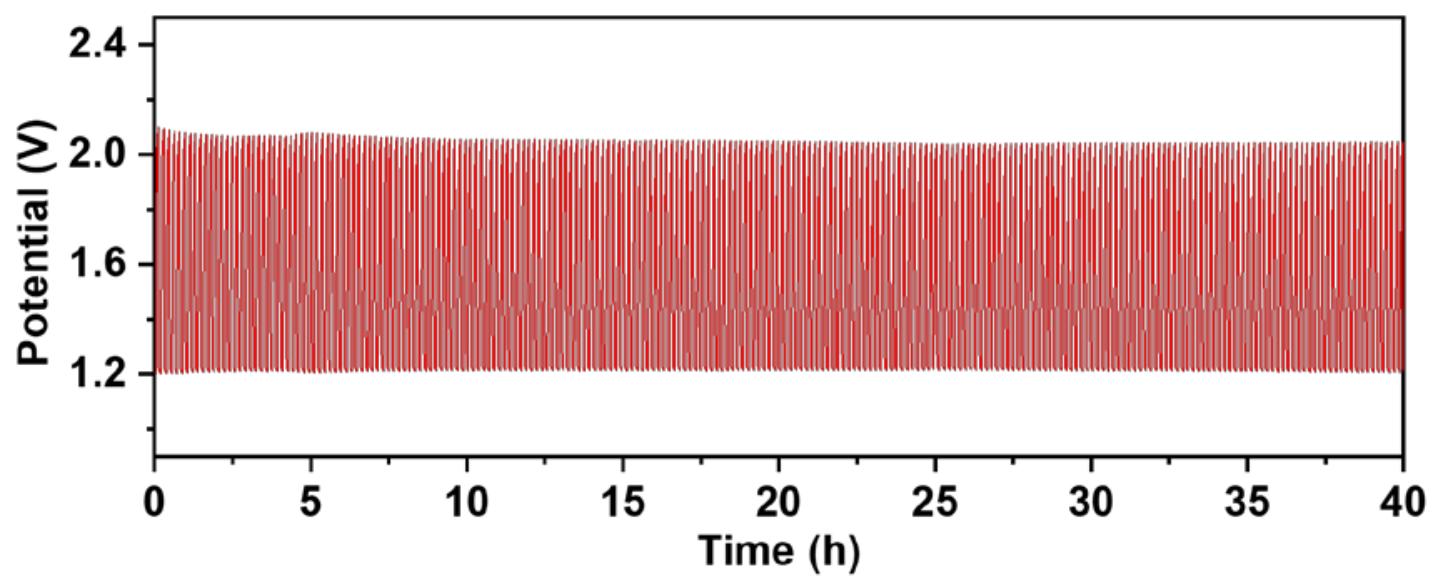

Figure S41. Galvanostatic charge/discharge test of the rechargeable zinc-air battery built with Fe-N/P-C-700 catalyst at $10 \mathrm{~mA} \mathrm{~cm}^{-2}$. 
(a)

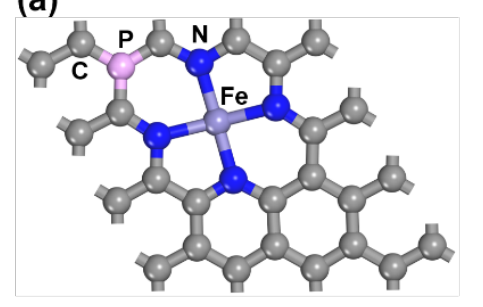

(d)



(b)

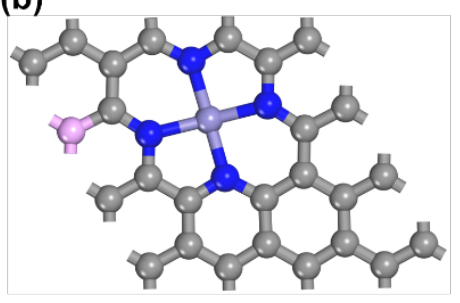

(e)



(c)

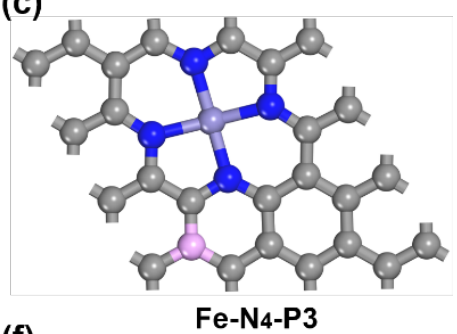

(f)



Figure S42. Computational models of Fe- $\mathrm{N}_{4}$ active sites with different positions of $\mathrm{P}$ dopant. (a) Fe-N4-P1, (b) Fe-N4-P2, (c) Fe-N4-P3, (d) Fe-N4-P4, (e) Fe-N4-P5, and (f) FeN4-P6. 
(a)



(e)

Fe-N3P-P1

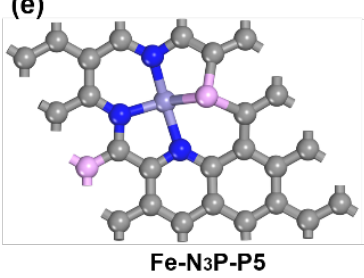

(b)

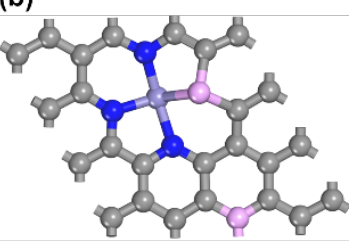

(c)

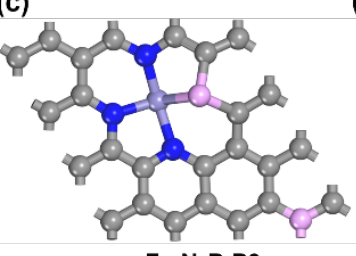

(d)


Fe-N3P-P7

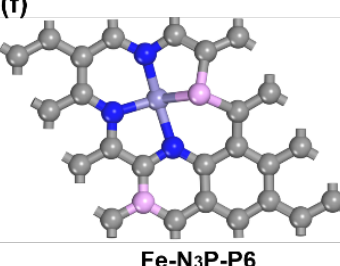

(h)
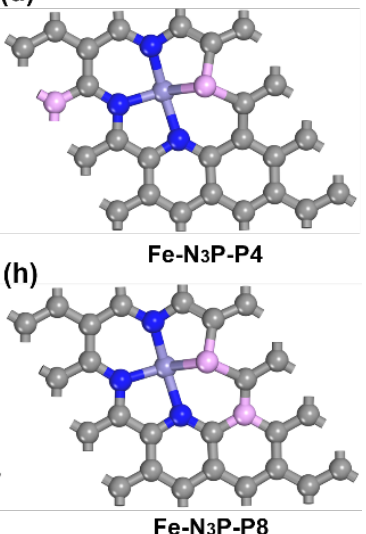

Figure S43. Computational models of $\mathrm{Fe}-\mathrm{N}_{3} \mathrm{P}$ active sites with different positions of $\mathrm{P}$ dopant. (a) Fe-N3P-P1, (b) Fe-N3P-P2, (c) Fe-N3P-P3, (d) Fe-N3P-P4, (e) Fe-N3P-P5, (f) Fe-N3P-P6, (g) Fe-N3P-P7, and (h) Fe-N3P-P8. 




Reaction coordinate

Figure S44. The Gibbs free energy diagrams of ORR on Fe- $\mathrm{N}_{4}$ active site with different positions of P dopant. 


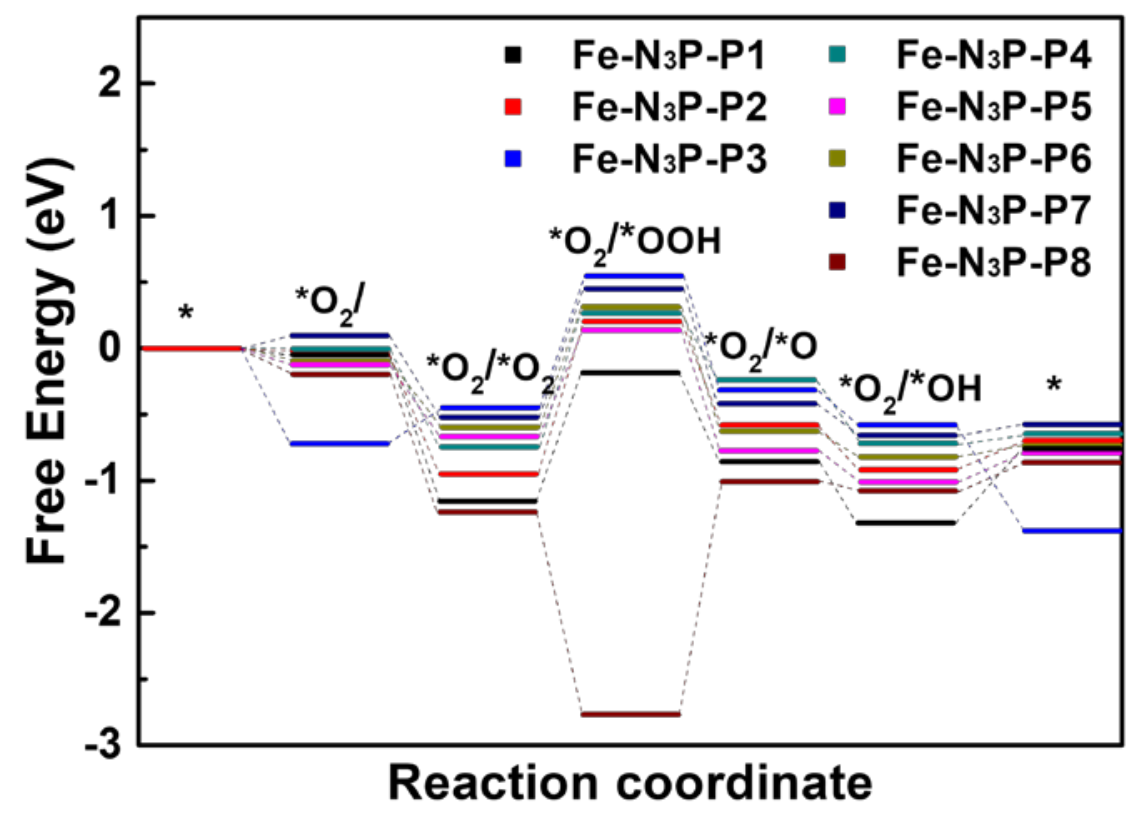

Figure S45. The Gibbs free energy diagrams of $\mathrm{ORR}$ on $\mathrm{Fe}-\mathrm{N}_{3} \mathrm{P}$ active site with different positions of P dopant. 


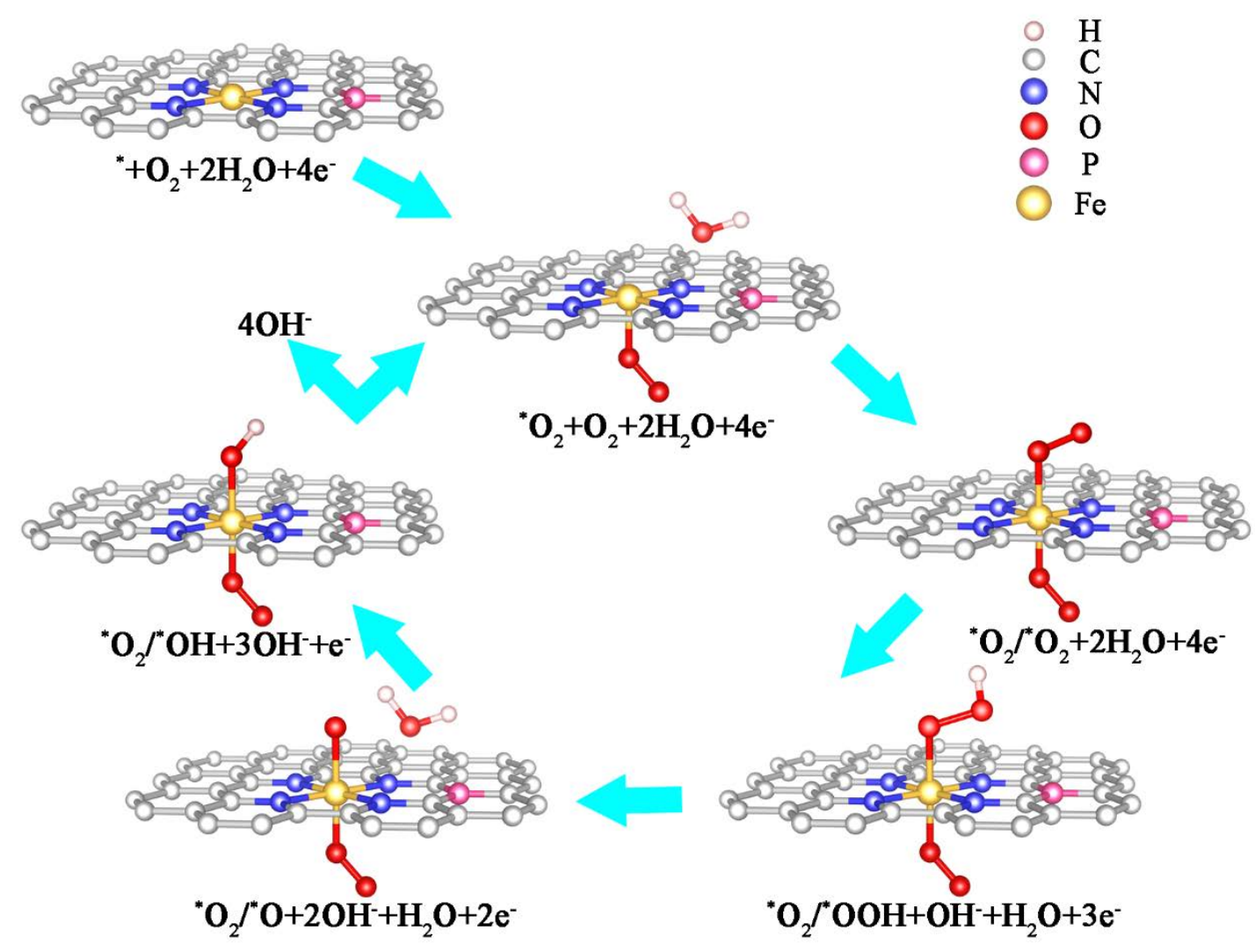

Figure S46. ORR catalytic mechanism on $\mathrm{Fe}-\mathrm{N}_{4}-\mathrm{P} 1$ active site. 
Table S1. Elemental contents of C, N, O, P and Fe based on XPS analysis ICP-OES for Fe-N/P-C catalysts.

\begin{tabular}{cccccc}
\hline \multirow{2}{*}{ Sample } & \multicolumn{5}{c}{ Chemical composition (at\%) } \\
\cline { 2 - 6 } & $\mathrm{C}$ & $\mathrm{N}$ & $\mathrm{O}$ & $\mathrm{P}$ & $\mathrm{Fe}$ \\
\hline Fe-N/P-C-600 & 87.93 & 5.97 & 5.08 & 0.59 & 0.43 \\
Fe-N/P-C-700 & 88.08 & 4.71 & 4.13 & 2.05 & 1.03 \\
Fe-N/P-C-800 & 88.14 & 3.97 & 4.02 & 2.17 & 1.7 \\
Fe-N/P-C-900 & 89.19 & 3.48 & 3.77 & 2.39 & 2.17 \\
Fe-N/P-C-1000 & 89.34 & 2.76 & 3.15 & 2.49 & 2.26 \\
\hline
\end{tabular}


Table S2. EXAFS data fitting results of Fe-N/P-C-700 and Fe-N/P-C-800.

\begin{tabular}{|c|c|c|c|c|c|c|}
\hline Sample & Path & $N$ & $R(\AA)$ & $\sigma^{2}\left(10^{-3} \AA^{2}\right)$ & $\Delta E_{0}$ & $R$-factor \\
\hline \multirow{3}{*}{ Fe-N/P-C-700 } & Fe-N & $3.1 \pm 0.3$ & 1.99 & $2.49 \pm 0.18$ & \multirow{2}{*}{$-2.0 \pm 1.1$} & \multirow{2}{*}{0.02} \\
\cline { 2 - 6 } & Fe-P & $0.9 \pm 0.1$ & 2.35 & $2.49 \pm 0.18$ & & \\
\hline \multirow{3}{*}{ Fe-N/P-C-800 } & Fe-P & $2 \pm 0.2$ & 2.19 & $8.71 \pm 0.45$ & & \multirow{2}{*}{0.017} \\
\cline { 2 - 6 } & Fe-P & $4 \pm 0.3$ & 2.28 & $8.71 \pm 0.45$ & \multirow{2}{*}{$2.4 \pm 3.4$} & \\
\cline { 2 - 6 } & Fe-Fe & $2 \pm 0.3$ & 2.57 & $2.22 \pm 0.30$ & & \\
\cline { 2 - 6 } & Fe-Fe & $4 \pm 0.4$ & 2.67 & $2.22 \pm 0.30$ & & \\
\hline
\end{tabular}

$N$, coordination number; $R$, distance between absorber and backscatter atoms; $\sigma^{2}$,

Debye-Waller factor to account for both thermal and structural disorders; $\Delta E_{0}$, inner potential correction; $R$-factor (\%) indicates the goodness of the fit. Sample Fe-N/P-C700 fitting range: $1.45 \AA^{-1}<k<10.64 \AA^{-1}$ and $1 \AA<R<2.26 \AA$. Sample Fe-N/P-C800 fitting range : $2.20 \AA^{-1}<k<10.67 \AA^{-1}$ and $1 \AA<R<3.27 \AA$. 
Table S3. Summary of the Mössbauer parameters and assignments to different iron species in Fe-N/P-C-700 electrocatalyst.

\begin{tabular}{ccccc}
\hline Fe species & $I S(\mathrm{~mm} / \mathrm{s})$ & QS $(\mathrm{mm} / \mathrm{s})$ & $L W(\mathrm{~mm} / \mathrm{s})$ & Content $(\%)$ \\
\hline Fe-S1 & 0.16 & - & 0.54 & 18.9 \\
Fe-D1 & 0.67 & 0.49 & 0.54 & 37.7 \\
Fe-D2 & 1.22 & 2.36 & 0.54 & 43.4 \\
\hline
\end{tabular}

Isomer shift (IS), quadrupole splitting $(Q S)$, line width $(L W)$ and relative content \% of each component.

Table S4. Summary of the $\mathrm{N}_{2}$ sorption data for the Fe-N/P-C catalysts prepared at different conditions.

\begin{tabular}{ccccccc}
\hline Samples & $\begin{array}{c}\mathrm{S}_{\text {BET }} \\
\left(\mathrm{m}^{2} / \mathrm{g}\right)\end{array}$ & $\begin{array}{c}\mathrm{S}_{\text {micro }} \\
\left(\mathrm{m}^{2} / \mathrm{g}\right)\end{array}$ & $\begin{array}{c}\mathrm{S}_{\text {meso }} \\
\left(\mathrm{m}^{2} / \mathrm{g}\right)\end{array}$ & $\begin{array}{c}\mathrm{V}_{\text {total }} \\
\left(\mathrm{cm}^{3} / \mathrm{g}\right)\end{array}$ & $\begin{array}{c}\mathrm{V}_{\text {micro }} \\
\left(\mathrm{cm}^{3} / \mathrm{g}\right)\end{array}$ & $\begin{array}{c}\mathrm{V}_{\text {meso }} \\
\left(\mathrm{cm}^{3} / \mathrm{g}\right)\end{array}$ \\
\hline Fe-N/P-C-600 & 810 & 725 & 85 & 0.55 & 0.27 & 0.28 \\
Fe-N/P-C-700 & 828 & 735 & 93 & 0.61 & 0.28 & 0.33 \\
Fe-N/P-C-800 & 675 & 598 & 77 & 0.45 & 0.22 & 0.23 \\
Fe-N/P-C-900 & 354 & 306 & 48 & 0.25 & 0.12 & 0.13 \\
Fe-N/P-C-1000 & 401 & 339 & 62 & 0.25 & 0.13 & 0.12 \\
\hline
\end{tabular}


Table S5. Comparison of ORR catalytic activities between Fe-N/P-C-700 and other well-developed Fe-based ORR electrocatalysts in $0.1 \mathrm{M} \mathrm{KOH}$.

\begin{tabular}{|c|c|c|c|}
\hline Electrocatalysts & $\begin{array}{c}E_{\text {onset }} \\
(\mathrm{V} \text { vs. RHE) }\end{array}$ & $\begin{array}{c}E_{1 / 2} \\
(\mathrm{~V} \text { vs. RHE) }\end{array}$ & Reference \\
\hline Fe-N/C catalyst & 0.923 & 0.809 & J. Am. Chem. Soc. 2014, 136, 1102. \\
\hline $\begin{array}{l}\mathrm{Fe}_{3} \mathrm{C} @ \mathrm{Fe}-\mathrm{N} \text {-doped } \\
\mathrm{CNFs}\end{array}$ & 0.94 & 0.82 & Angew. Chem. Int. Ed. 2015, 127, 8297. \\
\hline Fe-N/C-800 & --- & 0.81 & J. Am. Chem. Soc. 2015, 137, 5555. \\
\hline Fe-N-C-2HT-1AL & 0.92 & 0.82 & Nat. Commun. 2015, 6, 8618. \\
\hline $\begin{array}{l}\text { Fe-N-doped graphene } \\
\text { aerogels }\end{array}$ & 0.97 & 0.82 & Adv. Funct. Mater. 2016, 26, 5708. \\
\hline Fe-N-CC & 0.94 & 0.83 & ACS Nano 2016, 10, 5922. \\
\hline $\mathrm{Fe} / \mathrm{N}-\mathrm{CNFs}$ & 0.88 & 0.79 & Small 2016, 12, 6398. \\
\hline$(\mathrm{Fe}, \mathrm{Co}) / \mathrm{N}-\mathrm{C}$ & 1.06 & 0.863 & J. Am. Chem. Soc. 2017, 139, 17281. \\
\hline $\mathrm{Fe}-\mathrm{ISAs} / \mathrm{CN}$ & 0.986 & 0.900 & Angew. Chem. Int. Ed. 2017, 56, 6937. \\
\hline $\mathrm{S}, \mathrm{N}-\mathrm{Fe} / \mathrm{N} / \mathrm{C}-\mathrm{CNT}$ & 0.96 & 0.85 & Angew. Chem. Int. Ed. 2017, 56, 610. \\
\hline $\mathrm{Fe} / \mathrm{N} / \mathrm{C}$ & 1.1 & 0.93 & ACS Catal., 2017, 7, 6485. \\
\hline NFe/CNs-800 & 0.867 & 0.764 & Adv. Mater. 2017, 29, 1700707 \\
\hline p-Fe-N-CNFs & 0.91 & 0.82 & Energy Environ. Sci. 2018, 11, 2208. \\
\hline FeNC-S-FexC/Fe & 1.05 & 0.873 & Adv. Mater. 2018, 30, 504 \\
\hline Fe-N-DSC & 1.025 & 0.83 & ACS Nano 2018, 12, 208. \\
\hline Fe@Aza-PON & --- & 0.84 & J. Am. Chem. Soc. 2018, 140, 1737. \\
\hline$(\mathrm{Fe}, \mathrm{Co}) / \mathrm{CNT}$ & 1.05 & 0.954 & Energy Environ. Sci. 2018, 11, 3375. \\
\hline Fe-SAs/NPS-HC & --- & 0.912 & Nat. Commun. 2018, 9, 5422. \\
\hline $\mathrm{SA}-\mathrm{Fe} / \mathrm{NG}$ & 1.0 & 0.88 & $\begin{array}{l}\text { Proc. Natl. Acad. Sci. U.S.A 2018, 115, } \\
6626 .\end{array}$ \\
\hline Fe2-Z8-C & 0.985 & 0.871 & Angew. Chem. Int. Ed. 2018, 57, 1204. \\
\hline FeCl1N4/CNS & --- & 0.921 & Energy Environ. Sci. 2018, 11, 2348. \\
\hline $\mathrm{Fe}_{0}-\mathrm{N}-\mathrm{C}$ & --- & 0.795 & Angew. Chem. Int. Ed. 2018, 57, 8525. \\
\hline CNT@f-FeNC170 & 0.97 & 0.84 & Energy Environ. Sci. 2019, 12, 1317. \\
\hline Fe-N-C-800 & --- & 0.883 & J. Mater. Chem. A, 2019, 7, 11007. \\
\hline SC-Fe & --- & 0.869 & Angew. Chem., Int. Ed. 2019, 58, 4963. \\
\hline $\mathrm{Fe}_{0.5}-\mathrm{N}-\mathrm{C}$ & --- & 0.92 & J. Am. Chem. Soc. 2019, 141, 2035. \\
\hline Fe-N-C HNSs & 1.046 & 0.87 & Adv. Mater. 2019, 31, e1806312. \\
\hline Fe-NC SAC & 0.98 & 0.90 & Nat. Commun. 2019, 10, 1278. \\
\hline Fe-N/P-C-700 & 0.941 & 0.867 & This work \\
\hline
\end{tabular}


Table S6. Comparison of ORR catalytic activities between Fe-N/P-C-700 and other well-developed Fe-based ORR electrocatalysts in acid media.

\begin{tabular}{|c|c|c|c|}
\hline Electrocatalysts & $\begin{array}{c}E_{\text {onset }} \\
(\mathrm{V} \text { vs. RHE) }\end{array}$ & $\begin{array}{c}E_{1 / 2} \\
(\mathrm{~V} \text { vs. RHE) }\end{array}$ & Reference \\
\hline PANI-Fe-C & $0.91-0.93$ & 0.81 & Science 2011, 332, 443 \\
\hline $\mathrm{Fe}_{3} \mathrm{C} / \mathrm{C}-700$ & 0.9 & 0.73 & Angew. Chem., Int. Ed. 2014, 53, 3675. \\
\hline Fe-N/C-800 & 0.78 & 0.61 & J. Am. Chem. Soc. 2014, 136, 11027. \\
\hline $\begin{array}{l}\mathrm{Fe}_{3} \mathrm{C} @ \mathrm{Fe}-\mathrm{N} \text {-doped } \\
\mathrm{CNFs}\end{array}$ & 0.793 & 0.608 & Angew. Chem. Int. Ed. 2015, 54, 8179. \\
\hline Fe-N-CC & 0.80 & 0.52 & ACS Nano 2016, 10, 5922. \\
\hline $\mathrm{Fe}-\mathrm{N}-\mathrm{C}$ & 0.83 & 0.68 & J. Am. Chem. Soc. 2016, 138, 635. \\
\hline (CM+PANI)-Fe-C & 0.95 & 0.80 & Science 2017, 357, 479 \\
\hline Fe-N-C-Phen & -- & 0.67 & Adv. Mater. 2017, 29, 1604456. \\
\hline FeTMPPCl carbon & 0.824 & 0.748 & Adv. Funct. Mater. 2017, 27, 1604356. \\
\hline $\mathrm{Fe} \mathrm{SAs} / \mathrm{N}-\mathrm{C}$ & 0.95 & 0.75 & J. Am. Chem. Soc. 2017, 139, 17281. \\
\hline Fe@Aza-PON & -- & 0.541 & J. Am. Chem. Soc. 2018, 140, 1737. \\
\hline up-Fe-N-CNFs & 0.81 & 0.68 & \multirow{2}{*}{ Energy Environ. Sci. 2018, 11, 2208.} \\
\hline $\mathrm{p}-\mathrm{Fe}-\mathrm{N}-\mathrm{CNFs}$ & 0.85 & 0.74 & \\
\hline Fe-N-DSC & 0.853 & 0.699 & ACS Nano 2018, 12, 208. \\
\hline Z8-Fe2-C & 0.87 & 0.77 & Angew. Chem. Int. Ed. 2018, 57, 1204. \\
\hline $\mathrm{Fe}_{\mathrm{SA}}-\mathrm{N}-\mathrm{C}$ & --- & 0.776 & Angew. Chem. Int. Ed. 2018, 57, 8525. \\
\hline Fe-N-C-800 & --- & 0.723 & J. Mater. Chem. A, 2019, 7, 11007. \\
\hline$\odot .05 \mathrm{Fe}-\mathrm{ZIF}$ & 0.92 & 0.77 & Energy Environ. Sci. 2019, 12, 2548. \\
\hline TPI@Z8-650-C & --- & 0.811 & Nat. Catal. 2019, 2, 259-268. \\
\hline FeNC-S-MSUFC-2 & --- & 0.73 & J. Am. Chem. Soc. 2019, 141, 6254. \\
\hline $\begin{array}{l}\text { FeTMPPCl derived } \\
\text { Fe-N-C }\end{array}$ & 0.790 & 0.668 & Angew. Chem. Int. Ed. 2019, 58, 10486. \\
\hline Fe-N/P-C-700 & 0.89 & 0.72 & This work \\
\hline
\end{tabular}


Table S7. Comparison of ORR catalytic activities between Fe-N/P-C-700 and other well-developed Fe-based ORR electrocatalysts in both $0.1 \mathrm{M} \mathrm{KOH}$ and acid media.

\begin{tabular}{|c|c|c|c|}
\hline Electrocatalysts & $\begin{array}{c}E_{1 / 2} \\
(\mathrm{~V} \text { vs. RHE) } \\
0.1 \mathrm{M} \mathrm{KOH}\end{array}$ & $\begin{array}{c}E_{1 / 2} \\
(\mathrm{~V} \text { vs. RHE) } \\
\text { acid media }\end{array}$ & Reference \\
\hline Fe-N/C-800 & 0.81 & 0.59 & J. Am. Chem. Soc. 2014, 136, 11027. \\
\hline СРМ-99Fe/C & 0.80 & 0.72 & J. Am. Chem. Soc. 2015, 137, 2235. \\
\hline $\mathrm{PCN}-\mathrm{FeCo} / \mathrm{C}$ & 0.85 & 0.76 & Adv. Mater. 2015, 27, 3431. \\
\hline $\begin{array}{l}\mathrm{Fe}_{3} \mathrm{C} @ \mathrm{Fe}-\mathrm{N} \text {-doped } \\
\text { CNFs }\end{array}$ & 0.82 & 0.608 & Angew. Chem. Int. Ed. 2015, 127, 8297. \\
\hline Fe-N/C-800 & 0.81 & $\sim 0.6$ & J. Am. Chem. Soc. 2015, 137, 5555. \\
\hline $\begin{array}{l}\text { FePhen@MOF- } \\
\mathrm{ArNH}_{3}\end{array}$ & 0.86 & 0.77 & Nat. Commun. 2015, 6, 7343. \\
\hline Fe@C-FeNC-2 & 0.89 & 0.72 & J. Am. Chem. Soc. 2016, 138, 3570. \\
\hline Fe-N-CC & 0.83 & 0.52 & ACS Nano 2016, 10, 5922. \\
\hline$(\mathrm{Fe}, \mathrm{Co}) / \mathrm{N}-\mathrm{C}$ & 0.863 & 0.75 & J. Am. Chem. Soc. 2017, 139, 17281. \\
\hline Fe-ISAs/CN & 0.900 & 0.765 & Angew. Chem. Int. Ed. 2017, 56, 6937. \\
\hline Fe@Aza-PON & 0.84 & $<0.6$ & J. Am. Chem. Soc. 2018, 140, 1737. \\
\hline p-Fe-N-CNFs & 0.82 & 0.74 & Energy Environ. Sci. 2018, 11, 2208 \\
\hline Fe-SAs/NPS-HC & 0.912 & 0.791 & Nat. Commun. 2018, 9, 5422. \\
\hline $\mathrm{SA}-\mathrm{Fe} / \mathrm{NG}$ & 0.88 & 0.8 & $\begin{array}{l}\text { Proc. Natl. Acad. Sci. U.S.A 2018, 115, } \\
6626 .\end{array}$ \\
\hline Fe2-Z8-C & 0.871 & 0.77 & Angew. Chem. Int. Ed. 2018, 57, 1204. \\
\hline $\mathrm{Fe}_{0}-\mathrm{N}-\mathrm{C}$ & 0.795 & 0.776 & Angew. Chem. Int. Ed. 2018, 57, 8525. \\
\hline Fe-N-C-800 & 0.883 & 0.723 & J. Mater. Chem. A, 2019, 7, 11007. \\
\hline $\mathrm{Fe}_{0.5}-\mathrm{N}-\mathrm{C}$ & 0.92 & $\sim 0.75$ & J. Am. Chem. Soc. 2019, 141, 2035. \\
\hline Fe-NC SAC & 0.90 & $<0.7$ & Nat. Commun. 2019, 10, 1278. \\
\hline Fe-N/P-C-700 & 0.867 & 0.72 & This work \\
\hline
\end{tabular}


Table S8. Reaction energetics (eV) for the 4-elctron transfer processes during ORR on Fe- $\mathrm{N}_{4}$ and $\mathrm{Fe}-\mathrm{N}_{3} \mathrm{P}$ at $\mathrm{T}=298 \mathrm{~K}, \mathrm{pH}=13$, and $U=0 \mathrm{~V}$.

\begin{tabular}{ccc}
\hline Elementary reactions & Fe-N & Fe-N $3 \mathrm{P}$ \\
\hline $\mathrm{O}_{2}(\mathrm{~g})+* \rightarrow \mathrm{O}_{2}$ & -1.19202 & -1.00579 \\
$* \mathrm{O}_{2}+\mathrm{H}_{2} \mathrm{O}(\mathrm{l})+\mathrm{e}^{-} \longrightarrow{ }^{*} \mathrm{OOH}+$ & 0.68737 & 0.49291 \\
$\mathrm{OH}^{-}$ & & \\
$* \mathrm{OOH}+\mathrm{e}^{-} \longrightarrow * \mathrm{O}+\mathrm{OH}^{-}$ & -0.97176 & -1.07609 \\
$* \mathrm{O}+\mathrm{H}_{2} \mathrm{O}(\mathrm{l})+\mathrm{e}^{-} \longrightarrow * \mathrm{OH}+\mathrm{OH}^{-}$ & -0.21072 & 0.07535 \\
$* \mathrm{OH}+\mathrm{e}^{-} \longrightarrow \mathrm{OH}^{-}+*$ & 1.01956 & 0.84604 \\
\hline
\end{tabular}

Table S9. Reaction energetics (eV) for the 4-elctron transfer processes during ORR on $\mathrm{Fe}^{-N_{4}}(U=1.02 \mathrm{~V})$ and $\mathrm{Fe}-\mathrm{N}_{3} \mathrm{P}(U=0.85 \mathrm{~V})$ at $\mathrm{T}=298 \mathrm{~K}, \mathrm{pH}=13$.

\begin{tabular}{ccc}
\hline Elementary reactions & $\mathrm{Fe}_{4}(\mathrm{U}=1.02)$ & $\mathrm{Fe}-\mathrm{N}_{3} \mathrm{P}(\mathrm{U}=0.85)$ \\
\hline $\mathrm{O}_{2}(\mathrm{~g})+* \rightarrow \mathrm{O}_{2}$ & -2.21202 & -1.85579 \\
$* \mathrm{O}_{2}+\mathrm{H}_{2} \mathrm{O}(\mathrm{l})+\mathrm{e}^{-} \longrightarrow * \mathrm{OOH}+$ & -0.33263 & -0.35708 \\
$\mathrm{OH}^{-}$ & & -1.92609 \\
$* \mathrm{OOH}+\mathrm{e}^{-} \longrightarrow * \mathrm{O}+\mathrm{OH}^{-}$ & -1.99176 & -0.77465 \\
$* \mathrm{O}+\mathrm{H}_{2} \mathrm{O}(\mathrm{l})+\mathrm{e}^{-} \longrightarrow{ }^{*} \mathrm{OH}+\mathrm{OH}^{-}$ & -1.23072 & -0.00396 \\
$* \mathrm{OH}+\mathrm{e}^{-} \longrightarrow \mathrm{OH}^{-}+*$ & -0.00044 &
\end{tabular}


Table S10. Reaction energetics $(\mathrm{eV})$ for the 4-elctron transfer processes during ORR on $\mathrm{Fe}-\mathrm{N}_{4}-\mathrm{O}_{2}$ and $\mathrm{Fe}-\mathrm{N}_{3} \mathrm{P}-\mathrm{O}_{2}$ at $\mathrm{T}=298 \mathrm{~K}, \mathrm{pH}=13$, and $U=0 \mathrm{~V}$.

\begin{tabular}{rcc}
\hline Elementary reactions & $\mathrm{Fe}-\mathrm{N}_{4}-\mathrm{O}_{2}$ & $\mathrm{Fe}-\mathrm{N}_{3} \mathrm{P}-\mathrm{O}_{2}$ \\
\hline $\mathrm{O}_{2}(\mathrm{~g})+* \longrightarrow * \mathrm{O}_{2}$ & -1.19202 & -1.00579 \\
$* \mathrm{O}_{2}+\mathrm{O}_{2}(\mathrm{~g}) \longrightarrow * \mathrm{O}_{2} / * \mathrm{O}_{2}$ & 1.36555 & 0.17821 \\
$* \mathrm{O}_{2} / * \mathrm{O}_{2}+\mathrm{H}_{2} \mathrm{O}(\mathrm{l})+\mathrm{e}^{-} \longrightarrow * \mathrm{O}_{2} / * \mathrm{OOH}+\mathrm{OH}^{-}$ & -0.49269 & 1.22461 \\
$* \mathrm{O}_{2} / * \mathrm{OOH}+\mathrm{e}^{-} \longrightarrow * \mathrm{O}_{2} / * \mathrm{O}+\mathrm{OH}^{-}$ & -0.44878 & -0.42965 \\
$* \mathrm{O}_{2} / * \mathrm{O}+\mathrm{H}_{2} \mathrm{O}(\mathrm{l})+\mathrm{e}^{-} \longrightarrow * \mathrm{O}_{2} / * \mathrm{OH}+\mathrm{OH}^{-}$ & -0.89444 & -0.67136 \\
$* \mathrm{O}_{2} / * \mathrm{OH}+\mathrm{e}^{-} \longrightarrow \mathrm{OH}^{-}+*$ & -0.19721 & -0.96938 \\
\hline
\end{tabular}

Table S11. Reaction energetics (eV) for the 4-elctron transfer processes during ORR on Fe- $\mathrm{N}_{4}-\mathrm{O}_{2}(U=1.36 \mathrm{~V})$ and $\mathrm{Fe}-\mathrm{N}_{3} \mathrm{P}-\mathrm{O}_{2}(U=1.22 \mathrm{~V})$ at $\mathrm{T}=298 \mathrm{~K}, \mathrm{pH}=13$.

\begin{tabular}{rcc}
\hline Elementary reactions & $\mathrm{Fe}-\mathrm{N}_{4}-\mathrm{O}_{2}$ & $\mathrm{Fe}-\mathrm{N}_{3} \mathrm{P}-\mathrm{O}_{2}$ \\
$\mathrm{O}_{2}(\mathrm{~g})+* \longrightarrow * \mathrm{O}_{2}$ & $(\mathrm{U}=1.36)$ & $(\mathrm{U}=1.22)$ \\
$* \mathrm{O}_{2}+\mathrm{O}_{2}(\mathrm{~g}) \longrightarrow * \mathrm{O}_{2} / * \mathrm{O}_{2}$ & -2.55202 & -2.22579 \\
$* \mathrm{O}_{2} / * \mathrm{O}_{2}+\mathrm{H}_{2} \mathrm{O}(\mathrm{l})+\mathrm{e}^{-} \longrightarrow \mathrm{O}_{2} / * \mathrm{OOH}+\mathrm{OH}^{-}$ & -1.85269 & -1.04179 \\
$* \mathrm{O}_{2} / * \mathrm{OOH}+\mathrm{e}^{-} \longrightarrow * \mathrm{O}_{2} / * \mathrm{O}+\mathrm{OH}^{-}$ & -1.80833 & -1.64965 \\
$* \mathrm{O}_{2} / * \mathrm{O}+\mathrm{H}{ }_{2} \mathrm{O}(\mathrm{l})+\mathrm{e}^{-} \longrightarrow * \mathrm{O}_{2} / * \mathrm{OH}^{-}+\mathrm{OH}^{-}$ & -2.25444 & -1.89136 \\
$* \mathrm{O}_{2} / * \mathrm{OH}+\mathrm{e}^{-} \longrightarrow \mathrm{OH}^{-}+*$ & -1.55721 & -2.18938 \\
\hline
\end{tabular}


Table S12. Reaction energetics (eV) for the 4-elctron transfer processes during ORR on Fe- $\mathrm{N}_{4}-\mathrm{P} 1-\mathrm{O}_{2}$ and $\mathrm{Fe}-\mathrm{N}_{3} \mathrm{P}-\mathrm{P} 5-\mathrm{O}_{2}$ at $\mathrm{T}=298 \mathrm{~K}, \mathrm{pH}=13$, and $U=0 \mathrm{~V}$.

\begin{tabular}{rcc}
\hline Elementary reactions & Fe-N $4-\mathrm{P}_{1}-\mathrm{O}_{2}$ & Fe-N 3 P-P5-O \\
\hline $\mathrm{O}_{2}(\mathrm{~g})+* \longrightarrow * \mathrm{O}_{2}$ & -0.86752 & -0.11615 \\
$* \mathrm{O}_{2}+\mathrm{O}_{2}(\mathrm{~g}) \longrightarrow * \mathrm{O}_{2} / * \mathrm{O}_{2}$ & 0.99497 & -0.53232 \\
$* \mathrm{O}_{2} / * \mathrm{O}_{2}+\mathrm{H}_{2} \mathrm{O}(\mathrm{l})+\mathrm{e}^{-} \longrightarrow * \mathrm{O}_{2} / * \mathrm{OOH}+\mathrm{OH}^{-}$ & -0.68099 & 0.78902 \\
$* \mathrm{O}_{2} / * \mathrm{OOH}+\mathrm{e}^{-} \longrightarrow * \mathrm{O}_{2} / * \mathrm{O}+\mathrm{OH}^{-}$ & -0.36216 & -0.92647 \\
$* \mathrm{O}_{2} / * \mathrm{O}+\mathrm{H}_{2} \mathrm{O}(\mathrm{l})+\mathrm{e}^{-} \longrightarrow * \mathrm{O}_{2} / * \mathrm{OH}+\mathrm{OH}^{-}$ & -0.77409 & -0.22702 \\
$* \mathrm{O}_{2} / * \mathrm{OH}+\mathrm{e}^{-} \longrightarrow \mathrm{OH}^{-}+*$ & 0.15470 & 0.22922 \\
\hline
\end{tabular}

